\title{
Which Europeans like Nudges? Approval and Controversy in Four European Countries
}

\author{
Loibl, Cäzilia; Sunstein, Cass R.; Rauber, Julius; Reisch, Lucia A.
}

Document Version

Accepted author manuscript

Published in:

Journal of Consumer Affairs

DOI:

10.1111/joca.12181

Publication date:

2018

License

Unspecified

Citation for published version (APA):

Loibl, C., Sunstein, C. R., Rauber, J., \& Reisch, L. A. (2018). Which Europeans like Nudges? Approval and Controversy in Four European Countries. Journal of Consumer Affairs, 52(3), 655-688.

https://doi.org/10.1111/joca.12181

Link to publication in CBS Research Portal

\section{General rights}

Copyright and moral rights for the publications made accessible in the public portal are retained by the authors and/or other copyright owners and it is a condition of accessing publications that users recognise and abide by the legal requirements associated with these rights.

Take down policy

If you believe that this document breaches copyright please contact us (research.lib@cbs.dk) providing details, and we will remove access to the work immediately and investigate your claim. 


\section{Which Europeans like Nudges? Approval and Controversy in Four European Countries}

\section{Cäzilia Loibl, Cass R. Sunstein, Julius Rauber, and Lucia A. Reisch}

Journal article (Accepted manuscript*)

\section{Please cite this article as:}

Loibl, C., Sunstein, C. R., Rauber, J., \& Reisch, L. A. (2018). Which Europeans like Nudges? Approval and Controversy in Four European Countries. Journal of Consumer Affairs, 5233), 655-688. 001: 10.1111/joca.12181

This is the peer reviewed version of the article, which has been published in final form at DOI:

$$
\text { https://doi.org/10.1111/joca.12181 }
$$

This article may be used for non-commercial purposes in accordance with Wiley Terms and Conditions for SelfArchiving

* This version of the article has been accepted for publication and undergone full peer review but has not been through the copyediting, typesetting, pagination and proofreading process, which may lead to differences between this version and the publisher's final version AKA Version of Record. 


\title{
Which Europeans like nudges? Approval and controversy in four European countries
}

\author{
Cäzilia Loibl \\ The Ohio State University, Department of Human Sciences \\ Columbus, Ohio U.S.A. \\ Cass R. Sunstein \\ Harvard Law School \\ Cambridge, Massachusetts, U.S.A. \\ Julius Rauber \\ Zeppelin University, Center for Consumers, Markets and Politics \\ Friedrichshafen, Germany \\ Lucia A. Reisch \\ Copenhagen Business School, Department of Management, Society and Communication \\ Frederiksberg, Denmark
}

Version accepted in the Journal of Consumer Affairs, December 26, 2017

\begin{abstract}
Policy-makers show an increasing interest in "nudges" - behaviorally motivated interventions that steer people in certain directions but maintain freedom of consumer choice. Despite this interest, little evidence has surfaced about which population groups support nudges and nudging. We report the results of nationally representative surveys in Denmark, Hungary, Italy, and the United Kingdom. Individual, household and geographic characteristics served as predictors of nudge approval, and the count of significant predictors as measures of controversy. Less high approval rates of nudges in Denmark and Hungary were reflected in higher controversy about "System 1" nudges, whereas the United Kingdom and Italy were marked by higher controversy about "System 2" nudges, despite high approval rates. High-controversy nudges tended to be associated with current public policy concerns, for example, meat consumption. The results point to means for effective targeting, and increase knowledge about the types of nudges likely to obtain public support.

\section{Acknowledgements}

The data collection for this study has been supported by Copenhagen Business School (CBS), Governing Responsible Business (GRB) Cluster at the Department of Management, Society and Communication. We thank GRB for its generous support.
\end{abstract}




\section{INTRODUCTION}

Policy-makers show an increasing interest in "nudges," which are commonly defined as behaviorally motivated interventions that steer people in certain directions but maintain freedom of consumer choice (Thaler and Sunstein 2008). Well-known examples of nudges are the programming of office printers to use double-sided printing as the default option (Egebark and Ekström 2016), and the placing of vivid and repulsive photos of tobacco-caused illnesses on cigarette boxes in order to deter people from smoking (Fong, Hammond, and Hitchman 2009). While supporters consider nudges a potentially effective and non-coercive alternative to regulations and bans because they "steer people in particular directions but ... also allow them to go their own way" (Sunstein Forthcoming, 1), opponents claim that some nudges can be insufficiently respectful of people's autonomy. In light of this debate, the question of support in a nation's population for nudges as a policy instrument to help people achieve long-term goals is an important one. Investigating this matter, Sunstein (Forthcoming) for the U.S. as well as Reisch and Sunstein (2016) for European countries find strong consumer support for 15 nudges related to health and environment topics. In a recent study, Sunstein, Reisch, and Rauber (2017) found similar majority approval of nudges by the populations in a sample of countries worldwide.

Building on these earlier studies, the present study investigates why consumers in selected European countries differ markedly in their attitudes toward behavioral nudges as policy tools employed by their national governments. The research question is derived from the findings of an earlier study (Reisch and Sunstein 2016) that compared the approval rates of 15 nudges in six European countries. The nudges are related to health, energy, and social welfare decisions (see Table 1). Results showed that, on average and across countries, about 9.56 (SD 3.569) of the 
15 nudges were approved by simple majority, ranging from an average of 7.8 nudges in Denmark to 10.7 nudges in Italy. ${ }^{1}$

These results motivated the question of why approval rates differed significantly across these European countries. In particular, a deeper investigation of potential reasons why approval rates in Denmark and Hungary were about 0.3 to 0.5 standard deviations lower, while those in the United Kingdom and Italy were about 0.2 to 0.3 standard deviations higher than the crosscountry average, might help us better understand and interpret the survey results. Consequently, the current study aims to address the possible role of individual socio-demographic, household, attitudinal, and geographic characteristics in determining these differences.

This research is among a small number of studies to explore the role of individual, household, and geographic characteristics for the approval of a range of nudges (Diepeveen et al. 2013, Felsen, Castelo, and Reiner 2013, Hagman et al. 2015, Jung and Mellers 2016, Junghans, Cheung, and Ridder 2015, Petrescu et al. 2016, Tannenbaum, Fox, and Rogers 2017). It complements recent findings on attitudes toward nudges (Jung and Mellers 2016) and contributes further insights into consumer responses to nudges (Reisch and Sunstein 2016). The study also focuses on four disparate countries, thus enabling a comparison of results across country borders in Europe. Other approaches have been to compare countries according to the behavior that was being targeted (Diepeveen et al. 2013), or to compare across welfare systems, such as that of Sweden and the U.S. (Hagman et al. 2015), or according to the success of a nudge intervention, such as in the U.K. and U.S. (Petrescu et al. 2016). Finally, this study benefits from large, country-representative sample sizes, adding validation strength to our results.

1. Independent sample t-tests were significant below the $5 \%$ level for all pairwise comparisons of country means; data were weighted; $\mathrm{N}=6,066$ 


\section{LITERATURE REVIEW}

\section{Definition and Categories of Nudges Used in This Study}

Thaler and Sunstein's (2008) book Nudge: Improving decisions about health, wealth and happiness states: "A nudge, as we will use the term, is any aspect of the choice architecture that alters people's behavior in a predictable way without forbidding any options or significantly changing their economic incentives. To count as a mere nudge, the intervention must be easy and cheap to avoid" (Thaler and Sunstein 2008, 6). In short, nudges aim at behavior change and decision-making while preserving freedom of choice (Marchiori, Adriaanse, and Ridder 2017).

Nudges might be and have been grouped in many different ways (for a review see Marchiori, Adriaanse, and Ridder 2017). An important, commonly accepted categorization follows dual-systems theories (Kahneman 2011). A nudge can be labeled "System 1" if it targets automatic, intuitive, often unconscious processes and passive decision-making, or "System 2" if it targets deliberate, thoughtful, rule-based evaluation and approval (Marchiori, Adriaanse, and Ridder 2017). Prominent examples of System 1 nudges are graphic warnings on cigarette boxes and default rules. Statistical information and factual disclosures, such as calorie labels and information campaigns, are System 2 nudges (Sunstein 2016).

A second way of grouping nudges is according to their level of intrusiveness in people's lives. This method has been used to yield five types, ranking nudges from less intrusive educational nudges (e.g., educational government campaigns) and governmentally mandated information nudges to default rules, choice architecture-based interventions, and manipulative stimuli in the form of subliminal advertisements (Reisch and Sunstein 2016). We caution that technically, the last type, manipulative stimuli, should not qualify as a nudge (because it does not 
sufficiently maintain freedom of choice), but the type was added in order to assess peoples' attitude toward the boundary of unethical influence (Reisch and Sunstein 2016).

\section{Role of Individual, Household, and Geographic Characteristics in Nudges Research}

In consumer policy, nudges are sometimes developed for general populations. But on occasion, they are applied to targeted population groups that might benefit from them, for example because of a lack of information, a behavioral bias of some identifiable kind, or a particular "bottleneck" in the decision-making process (Ly et al. 2013). Socio-economic and geographic characteristics of the target group may be among the relevant criteria, in addition to health, financial, environmental, or other contextual criteria. For example, nudges might be designed to help poor people, patients, parents, or those with high credit car bills. In principle and sometimes in practice, they can target specific age groups, particular income levels, women or men, and different household compositions, or they can focus on urban areas compared to rural areas (for an overview, see The World Bank 2015, The Behavioral Insights Team 2016, OECD 2017).

While socio-economic and geographic characteristics are investigated in the process of developing nudges, less attention has been paid to the role they play in the effectiveness of nudges. We know far less than we might about how different groups react to different nudges. There are several reasons for this gap. First, the main focus of the current literature in this field is on estimating the effectiveness of nudges by comparing responses of those who are exposed to nudges to those who are not. Typically, this research employs randomized controlled trials (RCT), which have not typically controlled for and analyzed socio-demographic consumer characteristics. As a result, systematic reviews and meta-analyses of RCT-tested nudges focus less on socio-demographic characteristics (Arno and Thomas 2016, Wilson et al. 2016). This lack of knowledge has been noted. A recent meta-analysis stated, after testing nudges in high- 
income countries, that it "is difficult to confidently ascertain the viability of these interventions in a low or middle-income country setting" (Arno and Thomas 2016, 5).

As a result, information is not readily available on which population groups to target and which ones to avoid (and rather target with other types of interventions) when introducing nudges in a country. Similarly, information on which nudges are more controversial than others, based on individual, household, and geographic characteristics in a country, has not been systematically evaluated beyond selected country samples (for a review see, Reisch and Sunstein 2016, Reisch, Sunstein, and Gwozdz 2017). This is our focus here.

A second reason for a lesser attention to socio-demographic predictors is based on a widespread belief about human psychology. Some of the biases that are addressed by nudges seem to be hard-wired into human beings, and in many cases, they can be found across population groups (Ariely 2008). To that extent, nudge interventions may not typically be perceived as needing to adjust to gender, income, or other socio-demographic factors (Halpern 2016). But it is important to be careful with this point. Some nudges may turn out to be more effective with some groups than with others; this is an empirical question.

A third reason that has been brought forward against targeting certain population groups with nudges is based on ethical, privacy, and confidentiality concerns. An example of ethical concerns would be reservations about nudges targeted to financially vulnerable women to increase the use of long-acting forms of contraception, potentially violating their reproductive rights (Lucke 2013). Privacy and confidentiality concerns have been expressed, for instance, about using digital nudges in social security administration and other Big Data analytic environments, pointing to the need for processes that protect personal information and individual rights (Gregor and Lee-Archer 2016, Yeung 2017). 
A fourth hindrance to the investigation of individual socio-demographic, household, and geographic characteristics involves the difficulty of obtaining results of nudge interventions for representative samples. For example, in the food-nudges literature, a recent systematic review of studies on nudges' effectiveness in changing dietary choices noted that sample sizes for $60 \%$ of the papers were below 100, and between 100 and 500 for another 31\% (Arno and Thomas 2016). In a recent review of food-placement choices, $50 \%$ of studies involved less than 100 participants (Bucher et al. 2016).

A few papers have analyzed approval rates of nudges among citizens, sometimes with nudges targeted at consumers (Diepeveen et al. 2013, Felsen, Castelo, and Reiner 2013, Hagman et al. 2015, Jung and Mellers 2016, Junghans, Cheung, and Ridder 2015, Petrescu et al. 2016, Tannenbaum, Fox, and Rogers 2017, Gyrd-Hansen and Kjær 2015). Individual, household, and geographic characteristics were addressed in two of the studies. Petrescu et al. (2016) controlled for gender, age, socio-economic status, education, and race in determining the approval of five nudges and did not find significant relationships for these measures. In contrast, Diepeveen et al. (2013) found consistently higher approval rates among women, older adults, and higher-income respondents for intrusive interventions intended to nudge behaviors related to alcohol, smoking, and nutrition. The study further found approval of restrictive policies to be higher among more authoritarian than democratic countries.

A few studies testing the effectiveness of nudges have reported systematic socioeconomic and geographic differences. For instance, studies found stronger effects of certain nudges for lower-income persons in workplace-based experiments (Haisley et al. 2012), for households with high socio-economic status in environmental nudging (Rivers, ShenstoneHarris, and Young 2017), for women in health nudging (Paloyo et al. 2015, Nørnberg et al. 
2016), and for individuals with some college education (but not a college degree) in paydaylending nudges (Bertrand and Morse 2011). No systematic review of studies is available on whether and to what extent individual, household, and geographic characteristics are correlated with the approval of nudges in health, education, finance, or environmental contexts.

\section{Controversy About Nudges}

From the normative point of view, nudges are increasingly discussed in the academic community, with occasional controversy as well as frequent endorsement. This is evidenced by the increasing number of papers on nudges in ethics journals, such as the American Journal of Bioethics. ${ }^{2}$ Several papers have found that among a country's population, the introduction of nudges by a government can cause reactions of approval and disapproval. First, approval of nudges has been related to the type of nudge. In general, and with important ramifications, people tend to prefer System 2 nudges (Sunstein 2016). ${ }^{3}$ This tendency toward preferring educative nudges that allow for deliberate decision-making might be explained by reference to people's preference for maintaining full agency with respect to their decisions, rather than relying on architectural interventions, such as default rules (Jung and Mellers 2016, Sunstein 2016). Similarly, less intrusive nudges, such as information campaigns and information mandates, tend to find higher approval, compared to default rules and the design of a specific choice architecture (Reisch and Sunstein 2016). Importantly, however, both have found strong majority support (Reisch and Sunstein 2016). .

Second, nudges may appeal because they respond to a salient interest or concern of certain groups. On this view, a nudge is not approved or disapproved as such; it receives

2. In this journal, "nudge" was mentioned in paper abstracts 649 times in 2016, 518 times in 2015, 478 times in 2014, compared to 256 times in 2008, the year Nudge was published.

3. Approval for System 1 nudges tends to increase once people are told how they work (Sunstein 2016). 
approval if and to the extent that people approve of the direction in which it nudges. An example is the social marketing campaign of the United Kingdom's government aimed to nudge families to better food choices. It was designed and enacted in a way that would appeal to families with children so they take an active role in addressing the obesity problem (Mulderrig 2017). In contrast, public campaigns in the United States and the United Kingdom to introduce a meat-free day per week have been shown to be perceived as too radical among a wider population, and as a result, they are opposed by population groups less interested in changing their diet (Morris, Kirwan, and Lally 2014).

Third, the appeal of nudges may also depend on people's prior experience with nudges. The establishment of behavioral insights teams in European government agencies indicates a greater interest in using behavioral insights for policy-making (Lourenço et al. 2016). Experiencing the introduction of nudges through public media reports may affect people's approval. ${ }^{4}$ In the current study, only the United Kingdom had a government-appointed "nudge unit" during the field time; and some Danish authorities had started to create ad hoc behavioral insights teams (Lourenço et al. 2016).

\section{The Current Study}

Against this backdrop, the objective of the current study was to assess the relationship between individual, household, and geographic characteristics and the attitudes toward a selection of 15 nudges. Our units of analysis were nationally representative samples of four European countries. We chose two contrasting groups for the in-depth analysis, namely the two countries with the less high approval rates toward nudges (i.e., Denmark and Hungary) as well as those two with the highest rates (i.e., the U.K. and Italy) from the study of Reisch and Sunstein (2016). Our

4. For example, from 2010 to 2017, British newspapers mentioned the "nudge unit" in 572 articles. 
empirical strategy was to examine each country individually. We selected this strategy because each country in our survey is described with a unique, country-specific set of individual, household, and geographic characteristics. To investigate significant predictors of nudge approval, we constructed three measures: (1) the overall approval of the 15 nudges, (2) the approval of System 1 and System 2 nudges, and (3) the approval of five different types of nudges categorized by level of intrusiveness into people's lives, following the approaches in earlier work (Sunstein Forthcoming, Reisch and Sunstein 2016). We advance the following research questions:

1. Which individual, household, and geographic characteristics are related to the approval of nudges in each of the four countries?

2. (a) Which individual, household, and geographic characteristics are related to approval of System 1 and System 2 nudges? (b) Are System 1 nudges more polarizing compared to System 2 nudges?

3. (a) Which individual, household, and geographic characteristics are related to approval of the five types of nudges? (b) Are more highly intrusive nudges more polarizing compared to less intrusive nudges?

When examining the 15 nudges, (a) is overall approval in a country related to higher polarization, and (b) is higher polarization related to national identities or concerns?

\section{METHODS}

\section{Data Collection}

The analyses are based on country-representative survey data for Denmark (834 observations), Hungary ( 852 observations), the United Kingdom (1,805 observations), and Italy (741 
observations). ${ }^{5}$ The surveys were conducted by the Germany-based market research company GfK during two consecutive weeks between August 31 and September 14, 2015. Data were collected in Denmark, the United Kingdom, and Italy as CAWI (Computer-Assisted Web Interview) omnibus surveys, and in Hungary as a CAWI ad hoc survey because GfK did not have access to an omnibus survey. We excluded data collected in Germany and France in the current study because they had close to average (over all countries) approval rates. Due to the rather balanced, non-controversial responses in Germany and France, the majority of regression models were statistically insignificant with regard to common goodness-of-fit measures, such as chi-square and pseudo-R-square statistics in the logistic regressions and R-square and ANOVA F statistics in the linear regressions.

The questionnaire was closed-ended, and the order of the 15 nudge items was randomized. Thirteen nudges were taken from the United States survey (Sunstein Forthcoming). Two nudges were added to reflect the European context: requiring supermarket chains to keep cashier areas free of sweets (Nudge 14) as well as requiring canteens in public institutions to have one meat-free day per week (Nudge 15). These two items were chosen because their introduction was being discussed in Europe before and during field time.

In addition to gaining responses to the 15 nudges, the survey included questions about several individual socio-demographic, household, and geographic characteristics. The type and number of variables and their response options were specific for each of the four countries. The list of standard demographic characteristics followed the conventions of the data collection agency in each country based on their script for general population surveys. As a result, the number of individual, household, and geographic variables differs across countries.

5. The sample sizes are smaller than in Reisch and Sunstein (2016) because observations with missing values were excluded. 
Weights were calculated to achieve face-to-face population-representative samples in the United Kingdom (rim weighting $^{6}$ ), Denmark (target weighting ${ }^{7}$ ), and Hungary (rim weighting). The samples are representative for age, gender, and region in all four countries, as well as social class in the United Kingdom and community size in Hungary. The weights were calculated by the market research agency and are used in descriptive and regression analyses. In Italy, representativeness for the online population was satisfied without weighting based on sample stratification methods. The Italian sample is representative for gender, age, and region of the population with online access.

\section{Dependent Variable: Approval of Nudges}

The 15 nudges evaluated in this study are presented in Table 1. Opinion about each nudge was queried separately on a single screen with each one introduced by the question: "Do you approve or disapprove of the following hypothetical policy?" Respondents could choose between "approve" and "disapprove."

For data analysis, we used continuous and binary-coded dependent variables. The continuous dependent variable was the number of approved nudges on our list of 15 nudges (Research Question 1). Binary-coded variables included less high/high approval of System 1 nudges, System 2 nudges (Research Question 2), less high/high approval of information campaigns nudges, governmentally mandated information nudges, default rule nudges, choice

\footnotetext{
6. Rim weighting is a popular weighting procedure that is used to reduce the problems of unrepresentative samples and non-response bias. This procedure is used if information is incomplete about each of the possible combinations of demographic characteristics that a researcher would like to use for the weighting. For instance, geographic region and age are known, but not the age distribution in a particular geographic region. The survey responses are "grossedup" in an iterative procedure along a series of rims that have been predefined about the population. As a result of the iterative procedure, each respondent gets a unique weight. For an easy-to-follow, step-wise illustration of rim weighting see Baxter (2016).

7. Target weighting is another popular weighting procedure. Target weighting is used if information about the target population is available for all combinations of the weighting matrix, while rim weighting is typically applied if information is missing. The sample is weighted according to the known target figures.
} 
architecture nudges, and manipulation (Research Question 3), and approval of each individual nudge (Research Question 4). The seven less high/high approval variables (Research Questions 2 and 3) were coded as 1, and labeled "high approval" if the sum of nudges was equal to or greater than the median value. Otherwise, the responses were coded 0 and labeled "less high approval." As illustrated in Table 1, System 1 nudges included eight nudges, System 2 nudges seven nudges, information campaign nudges and governmentally mandated information nudges three nudges each, default rules six nudges, choice architecture two nudges, and manipulation in the form of subliminal advertisement included one nudge.

[Table 1 about here]

\section{Independent Variables: Individual, Household, and Geographic Characteristics}

Thirteen individual, household, and geographic characteristics were collected in the four countries. Individual characteristics include age, gender, marital status, education, employment status, and profession. Household variables include household size, number of children, household income, and social class. Geographic variables include region, community size, and urban/rural location of residence. The coding of the variables was adjusted to the sample in each country. For example, income and region variables that had categories with small numbers of responses were merged to create about equal-sized categories. Age, household size and number of children were collected in the survey as continuous variables; all other variables were inquired about in categories. Age was recoded into categories to be able to identify how different age groups responded to the nudges. Tables 1 to 4 in the Appendix present the measures for each country, the coding of each measure, and the descriptive statistics for each country.

\section{Analysis Plan}


In order to investigate the first research question about the general role of demographic predictors, the sum of approval of all 15 nudges was regressed on each country's individual, household, and geographic variables using linear OLS regression analysis. The number of predictors ranged from 23 (Hungary) to 37(United Kingdom).

To investigate the second and third research questions, the approval of System 1 and 2 nudges and of the five types of nudges was regressed on each country's individual, household, and geographic variables using binary logistic regression analysis. The regressions were conducted separately for each country because each had a unique set of country-specific predictor variables. Regression results are shown in Tables 2 to 5. To assess the level of polarization about dual-systems and types of nudges, the type and number of significant predictor variables $(\mathrm{p}<0.05)$ were examined. A high degree of polarization implies that different groups or entities within a country approve the use of nudges in politics in a way that is systematically different. A population characterized by high polarization between the genders implies, for instance, that women tend to approve a particular nudge while men oppose it. If this is the case, we should see high approval rates among women in the sample for this particular nudge. As a result, the corresponding variable (gender) has to be significant in any type of regression model. However, if there is no polarization across gender, we cannot exploit information about gender to predict the average approval rate in the sample, which, in turn, would result in a non-significant estimator.

To investigate the fourth research question, each one of the 15 individual nudges was regressed on the individual, household, and geographic variables of each country. ${ }^{8}$ The type and number of significant predictors served as measures of polarization in a country $(\mathrm{p}<0.05)$. The

8.. These regression results are available upon request. 
most polarizing nudge in each country was identified to assess the role of country-specific identities on nudge approval.

\section{RESULTS}

Results are presented by country in increasing order of nudge approval, beginning with Denmark, which showed the least high approval rate for the 15 nudges, followed by Hungary, the United Kingdom, and Italy, which had the highest approval rate of the nudges based on unconditional descriptive statistics. A summary table of regression results is shown in the Appendix Table 5.

\section{Denmark}

The average unconditional approval rate of the 15 nudges in Denmark was $51.93 \%$, or 7.79 of the 15 nudges $(\mathrm{SD}=3.391)$, which is at the lower end of the generally high approval rates of the six European countries in the original survey. In the Danish sample, 30 individual, household, and geographic variables served as predictors in the analyses reported here. These variables were categorized into age, gender, household size, number of children, educational attainment, gross annual household income, and region. Descriptive statistics are presented in Appendix Table 1, and regression results are presented in Table 2.

In our investigation of the first research question, the R-squared measure showed that a modest $5.2 \%$ of variance in nudge approval could be explained by the predictor variables. The value of the adjusted R-squared was 0.021 , and the $\mathrm{F}$ statistic was significant at the $5 \%$

significance level. Statistically significant associations between overall approval rate and individual, household, and geographic variables were solely income-related and included five income categories. Contrary to expectations and findings in the literature (Diepeveen et al. 
2013), the higher-income groups were more likely to disapprove of the 15 nudges when compared to the lowest income category.

Investigating the second research question, we found that the Danes had the least high approval rates for System 1 (29\%) and System 2 nudges (72\%) among the four countries of this study. Approval of System 1 nudges was significantly predicted by 10 predictors (39\%) and System 2 nudges by five predictors (19\%) at the 5\% significance level, suggesting lower controversy regarding System 2 nudges, compared to System 1 nudges. Comparing the predictors of the two dual-systems nudges, we see that approval of both systems was strongly associated with income and age. With regard to System 1 nudges, all higher-income categories (compared to the lowest income category) were less likely to approve. The odds of disapproval were also higher among respondents in their 40s and 70s, compared to the youngest age category. Approval of System 2 nudges was significantly negatively associated with income, compared to the lowest income group. Danes with a high school degree only were also less likely to approve of System 2 nudges. With regard to positive response, strong approval was found for System 2 nudges among the 30s group.

Investigating the third research question, we found the most polarizing types, measured by the number of significant predictors, to be default rules (Type 3) and subliminal advertisement (Type 5), each with eight of 26 predictors being significant when excluding base categories in the count. Least polarizing were information campaign and information mandate nudges (two significant predictors at the 5\% level each). Regressions of the four types of nudges as well as subliminal advertisement on individual, household, and geographic variables documented the dominant role of income for the odds of disapproval of Types 1,2,3, and 5 . The strongest disapproval related to income was found for default rules. The results for subliminal 
advertisement differed from the other four types. Here, middle-age groups and Danes with higher educational attainment had higher odds of disapproving of this type (compared to Danes without a high school degree). Further, subliminal advertisement had higher odds of approval among male Danes and Danes with children.

Investigation of the fourth research question, across the 15 regressions and 26 predictors (excluding base categories) in each regression, showed that overall $20 \%$ of predictors were significant — the second-highest rate after the United Kingdom—indicating a relatively high level of controversy about nudges in Denmark, compared to the other three countries. A choice architecture nudge requiring a meat-free day in public canteens (\#15 in Table 1) had the highest number of significant predictors: a total of $46 \%$ of predictors $(n=12)$. Descriptive statistics show that this nudge had a low $30 \%$ unconditional approval rate. The odds of disapproving of a meatfree day were strongly associated with older age, higher household incomes, and the residents of the rural South Denmark region, compared to the capital city region. Odds of approving of this nudge were solely associated with mid-level educational attainment: the odds were higher among Danes holding a medium graduate/bachelor degree.

[Table 2 about here]

\section{Hungary}

The average unconditional approval rate of the 15 nudges in Hungary was $56 \%$, or 8.44 of the 15 nudges ( $\mathrm{SD}=3.753)$. In Hungary, 28 individual, household, and geographic variables were available to serve as predictors in the regressions, including measures of age, gender, educational attainment, monthly household income, social class, urban residence, and community size. Descriptive statistics are presented in Appendix Table 2, and regression results are presented in Table 3. 
In terms of the first research question, the R-squared measure showed that $5.7 \%$ of variance in nudge approval could be explained by the independent variables. The value of the adjusted R-squared was 0.031 ; the $\mathrm{F}$ statistic was significant at the $1 \%$ significance level. Statistically significant associations between overall approval rate and individual, household, and geographic variables were observed for four predictors (17.39\% of predictors). Overall approval rate of the 15 nudges was significantly and positively associated with urban residence and residence in smaller communities of 1,000 to 5,000 people. Male gender was associated with lower likelihood of approval.

Investigation of the second research question showed that Hungarians reported "high" approval of $40 \%$ of System 1 nudges and $72 \%$ of System 2 nudges. Approval of System 1 nudges was significantly predicted by five of the 23 predictor variables when excluding base categories in the count (22\% of predictor variables) and System 2 nudges by four variables (17\%), suggesting lower controversy regarding both systems, relative to the other three countries. Comparing the predictors of the two systems, we found that residents of small communities have higher odds of approving both systems. Hungarians in their 60s, males, and those living in smaller communities had higher odds of approving of System 1 nudges. In contrast, higher-income categories were associated with lower odds of System 1 approval. This response is similar to the responses of Danes. Approval of System 2 was unrelated to income. Urban residents had higher odds of approving System 2 nudges, while males and those in their 40s had lower odds of approval.

Investigating the third research question, we found that default rules (Type 3) were the most polarizing nudges, with five out of 23 predictors being significant $(21.74 \%$; excluding base categories), which is similar to the Danish results. Least polarizing were information campaign 
nudges (two significant predictors at the 5\% level). Age and geographic variables were the most frequent predictors.

Investigating the fourth research question, we noted that across the 15 regressions and 23 predictors in each regression (excluding base categories), $12 \%$ of predictors were significant, indicating a comparatively low level of controversy in Hungary in this analysis of four European countries. A government-mandated information nudge requiring traffic-light labels signaling healthiness of food (\#2 in Table 1) had the highest number of significant predictors at the 5\% significance level, a total of $20 \%$ of predictors $(n=6)$. The odds of approval increased with higher social class, urban residence, and residence in smaller communities of 1,000 to 2,000 residents, compared to Hungary's most populous capital region. Odds of disapproval were higher among middle-age (40 to 49 years) and male persons.

[Table 3 about here]

\section{United Kingdom}

The average unconditional approval rate of the 15 nudges in the United Kingdom was 69\%, or 10.28 nudges $(\mathrm{SD}=3.310)$. For the United Kingdom, a total of 37 individual, household, and geographic variables were available as predictors of the 15 nudges. They included measures of age, gender, marital status, educational attainment, employment status, annual gross household income, social class, and region. Descriptive statistics are presented in Appendix Table 3, and regression results are presented in Table 4.

In regard to the first research question, the R-squared measure showed that $3.9 \%$ of variance in nudge approval could be explained by the predictor variables. The value of the adjusted R-squared was 0.023; the F statistic was significant at the 5\% level. Statistically significant associations between approval rate and individual, household, and geographic 
variables were observed for five variables (17\% of predictors). Age group 60 to 69 years (compared to the youngest age category), male gender, and the Midlands region of the U.K. (compared to the Southeast region, which includes London) were negatively associated with approval of the 15 nudges. The two low-to-moderate annual gross household income categories were positively associated with approval of the 15 nudges, compared to the lowest income category.

Looking at the second research question, we see that Britons reported "high" approval of $53 \%$ of System 1 nudges and 91\% of System 2 nudges. Approval of System 1 nudges was significantly predicted by five of the 30 predictor variables when excluding base categories in the count (17\%) and System 2 nudges by the relatively large number of nine variables (30\%), pointing to higher polarization regarding System 2 nudges in the U.K. The level of polarization is similar to Italy, but higher compared to Denmark and Hungary. Comparison of the predictors of the two systems shows that both are associated with age and gender. The odds of approving System 1 nudges were lower among Britons over the age of 40 and male Britons. In contrast, the odds of approving System 2 nudges increased with age, particularly among the 30- to 60-yearold Britons, and were higher among female Britons. In addition, divorced/separated/widowed Britons and those with higher incomes had higher odds of approving System 2 nudges.

To investigate the third research question, we determined that the most polarizing type, measured by the number of significant predictors, was not a "real" nudge type but subliminal advertisement (Type 5), with nine out of 30 predictors being significant (30\%; excluding base categories). Least controversial was the choice architecture nudge (five significant predictors at the $5 \%$ level). Increasing age served as significant positive predictor for all five types, with 
approval by women and people with higher income being significantly stronger for four types of nudges.

Investigating the fourth research question, we found across the 15 regressions and 30 predictors in each regression that $21 \%$ of predictors were significant (excluding base categories). This is the highest percentage among the six countries originally included in the survey, indicating a relatively high level of polarization in the United Kingdom. A governmentmandated information campaign informing about high levels of salt in food (\#10 in Table 1) had the highest number of significant predictors, a total of $37 \%(n=11)$. The unconditional approval rate for this nudge was a high $87 \%$. An examination of predictors showed that this nudge had higher odds of support among middle-age groups 30 to 59 years, as well as higher-income groups, compared to the lowest income category. The odds of opposing this nudge were significant among male respondents, more highly educated persons, and residents of the Northwest and the Midlands.

[Table 4 about here]

\section{Italy}

The average unconditional approval rate of the 15 nudges in Italy was 72\%, or 10.73 of the 15 nudges ( $\mathrm{SD}=3.463)$. In Italy, 31 individual, household, and geographic variables were available to be entered into the regression analyses. They included age, gender, household size, presence of children, marital status, educational attainment, profession, net monthly household income, and region. Descriptive statistics are presented in Appendix Table 4, and regression results are presented in Table 5.

During investigation of the first research question, the R-squared measure showed that $5.3 \%$ of variance in nudge approval can be explained by the independent variables. The value of 
the adjusted R-squared was 0.02; the F statistic was significant at the $5 \%$ level. Statistically significant associations between approval rate and individual, household, and geographic variables were observed for four variables. Middle-income groups and unemployed/people working in non-typical professions were more likely to approve of the 15 nudges. Residents of the Northwest region were more likely to disapprove, compared to those living in the Italian central region.

Investigating the second research question, we found that Italians reported "high" approval of $61 \%$ of System 1 nudges and 90\% of System 2 nudges. Approval of System 1 nudges was significantly predicted by five of the 30 predictor variables (17\%) and System 2 nudges by the relatively large number of nine variables (30\%), indicating higher polarization regarding System 2 nudges, similar to the U.K. Comparison of the predictors of the two systems reveals that higher odds of approval for both seem to be associated with higher income. The odds of approving System 1 nudges were also higher among the group of unemployed Italians and those with non-traditional professions. Italians residing in the Northwest had lower odds of System 2 approval.

Investigating the third research question involved the most controversial type of intervention in Italy. As measured by the number of significant predictors, this was the manipulative stimuli of subliminal advertisement (Type 5), with four out of 25 predictors being significant when excluding base categories in the count (16\%); least controversial was the default rule nudges. A relatively small number of predictors were significant (9\% of predictors across the five regressions).

Investigating the fourth research question, we found across the 15 regressions and 25 predictors in each regression that $10.40 \%$ of predictors were significant (excluding base 
categories), only about half as many as in the United Kingdom and Denmark, indicating a lower level of polarization in Italy. A government campaign targeting childhood obesity emerged as the most polarizing one in Italy (\#7 in Table 1). A total of $32 \%$ of predictors were significant $(n=8)$. The unconditional approval rate for this nudge was a high $89 \%$. The odds of approving of a childhood obesity campaign were significantly higher among higher-income individuals, 40- to 49-year-olds, and the professional category of students, unemployed persons, and those with untypical professions (compared to self-employed persons).

[Table 5 about here]

\section{DISCUSSION AND CONCLUSION}

This research examined the role of individual, household, and geographic variables for the approval of nudges in four European countries. We investigated which of these variables were related to (1) the approval of all 15 nudges, (2) System 1 and System 2 nudges, and (3) five types of nudges. We also examined which individual nudges had a higher number of significant predictors in each country, as a measure of polarization in a population.

To the best of our knowledge, this is the first study to examine how a wide range of individual, household, and geographic characteristics influence the approval of as many as 15 nudges. Our independent variables predicted a modest amount of variance in the approval of all 15 nudges. A comparison of System 1 and 2 nudges shows that polarization was stronger for System 1 nudges in the two countries of Denmark and Hungary, which had less-high approval rates, compared to System 2 nudges. In contrast, polarization was stronger for System 2 nudges in the two high-approval countries of the United Kingdom and Italy. Comparing the four types of nudges as well as the manipulative stimuli of subliminal advertisement, we see that polarization was strongest for default rule nudges in the two countries with less high approval rates, and for 
subliminal advertisement in the two high-approval countries, as well as Denmark (in a tie with default rule nudges). In the next sections, we discuss potential implications of our findings for research and public policy.

Investigating Research Question 1, we found modest predictive power and modest model fit. Four (Hungary, Italy) and five significant predictors (Denmark, United Kingdom) emerged in the regressions. The associations of overall approval with household income, gender, and geographic characteristics were particularly strong. Household income was associated with approval in three of the four countries: low household income was correlated with nudge approval in Denmark while higher household income was correlated with nudge approval in the United Kingdom and Italy. There was no significant relationship in Hungary and the predictors' signs were inconsistent. The consistently positive relationship of higher household income and nudge approval in the United Kingdom and Italy aligns with earlier findings in the nudges literature (Diepeveen et al. 2013). It also parallels marketing research showing that households of higher socio-economic status are more likely to adopt nudges and are in general more adoptive of innovations (Woersdorfer and Kaus 2011, Laukkanen 2016, Rivers, Shenstone-Harris, and Young 2017). To explore why the role of income is different in the Danish sample, correlation analysis showed that the lowest Danish income group is particularly strongly and significantly correlated with the youngest age group (below 30 years of age), smaller household sizes, and lower educational attainment, compared to the British and Italian samples. We speculate that this finding may reflect a higher level of trust in the government and its welfare policies among lower-income, younger, and lower-educated individuals in Denmark.

Male gender was negatively associated with approval in Hungary, the United Kingdom and, marginally significantly, in Italy. This finding previously emerged in our baseline study 
(Reisch and Sunstein 2016) and was shown in other multi-country studies (Diepeveen et al. 2013). It confirms the well-documented gender differences in the adoption of certain innovations (Venkatesh, Morris, and Ackerman 2000). To explore the reasons for why gender differences emerged particularly strongly in the United Kingdom compared to the other three countries, correlation analysis indicated that male gender was particularly strongly associated with full-time employment and older age in the United Kingdom, compared to the other three countries. We speculate, tentatively, that the finding may reflect a particularly high level of self-confidence among male, older, fully employed Britons. A gender gap in self-confidence has been documented for the United Kingdom in general population surveys (Bleidorn et al. 2016) as well as, for instance, among British managers (ILM 2011).

Regional influences emerged for Italy, the United Kingdom, and Hungary, pointing to lower approval rates among non-metropolitan areas with significant industrial heritage (i.e., Italian Northwest, English Midlands). Our finding may reflect a working-class hesitancy toward the concept of nudges because it aims to place the burden of behavior change on the individual, rather than government institutions (Mulderrig 2017).

Our findings that the approval rates of a bundle of nudges depend on distinct population characteristics indicate that nudge-based policy interventions will benefit from testing and targeting. This finding speaks to the value of research-based "practitioners' guides" for designing effective nudges (e.g., List, Sadoff, and Wagner 2010, Ly et al. 2013, Giné et al. 2006, Duflo, Glennerster, and Kremer 2007). The European Joint Research Center's behavioral group has rightly called for an empirical "test-learn-adapt-share" approach in behavioral insights-based policies that takes into account the targets as well as the socio-economic and cultural settings 
(Lourenço et al. 2016). Similar suggestions on the policy process have been put forward recently by the OECD (2017) and The World Bank (2015), among others.

Investigating Research Question \#2- the approval of System 1 and 2 nudges - our findings suggest that in less high approval countries, if System 1 nudges are to be introduced, they may benefit from focused efforts to explain and justify such interventions. In high-approval countries, our findings indicate lower controversy about System 1 nudges and higher approval among a wider range of income and age groups of System 2 nudges. To that extent, our findings are in line with literature that documented higher approval for System 2 nudges (Jung and Mellers 2016, Sunstein 2016). Our findings highlight, however, that this approval can be based on either lower controversy (in less high approval countries) or a higher number of positive relationships (in high-approval countries).

In this respect, implications for consumer policy are twofold. In contrast to an earlier multi-country study (Diepeveen et al. 2013), the current study found that approval of nudges is not necessarily a function of the influence of a country's democratic or authoritarian leadership. Rather, lesser or higher approval of nudges might an independent product of public opinion, taken simply as such. We note parenthetically that in the current study, Denmark exemplified a government's interest in behaviorally motivated interventions (Chetty et al. 2014) and their critical assessment (e.g., Ploug, Holm, and Brodersen 2012).

Investigation of Research Question \#3 showed that the manipulative stimuli and default rule nudges had higher levels of polarization based on the relative count of significant predictors across countries. Governmentally mandated information nudges and choice architecture-based interventions showed similar levels of controversy, ranking second. The lowest relative level of controversy across the four countries was found for educational campaigns. These findings align 
with literature identifying a preference for educative or System 2 nudges (e.g., Jung and Mellers 2016).

In regard to Research Question \#4, less high approval in a country is not necessarily related to higher controversy. While it is true for Denmark, the findings for Hungary indicate that relatively lower approval can be associated with lower levels of polarization in the population. We note as well that Hungary had a smaller number of public institutions applying behavioral insights to policy. A recent report listed six public institutions in Hungary, compared to 15 in Denmark (Lourenço et al. 2016). Similarly, the current study documents that high approval of nudges can be associated with both relatively higher (U.K.) and lower polarization (Italy).

In each country, one of the 15 nudges was the most polarizing nudge with regard to the count of significant predictor variables $(\mathrm{p}<0.05)$ - and it was a different nudge in each country. The high-controversy nudges tended to be associated with current public policy concerns in the countries. Meat-free day (\#15, Table 1) was the most polarizing nudge in Denmark, possibly reflecting public discourse about the role of pork meat in Danish food culture (Agence FrancePresse 2016). A "traffic light" system for food (\#2) was the most polarizing nudge in Hungary, possibly reflecting consumer concern about a Public Health Tax on Food Products introduced in Hungary in 2011, which led to a 29\% price increase (OECD 2014). Placing labels on products that have unusually high levels of salt (\#10) was the most polarizing nudge in the U.K. and may indicate public unease about proposed taxation of sodium-rich food (Public Health England 2016). In Italy, the most polarizing nudge was a public education campaign to reduce childhood obesity (\#7), reflecting a widespread public concern about Italy being one of the OECD countries with the highest levels (OECD 2015). (Note, however, that under our definitions, a polarizing 
nudge might also have high approval rates; for example, men and women might be polarized even if 70 percent of men approve and 95 percent of women do so.)

We would like to note that the current study was limited by the use of cross-sectional data that did not allow testing for causal relationships. In addition, this study investigated only health and environmental nudges, excluding, for instance, financial nudges. Further, the study was based on a unique set of predictors for each country. While this provided country-specific information, it limited statements about the generalizability of the findings. Also noteworthy, the data were based on self-reporting of subjects and limited to participants of commercially maintained consumer panels. It is possible that the survey questions led to socially-desirable, biased responses (Sudman and Wansink 2002). Because nudges have cultural dimensions, findings for the four countries may not apply to other countries or cultures.

Despite these limitations, the present research provides highly suggestive evidence that for nudges, approval rates are related to individual, household, and geographic characteristics. The role of these characteristics varies across nudges and nations. For that reason, it should be plain that generalizations are hazardous. To be sure, some larger patterns emerge, with strong majority support for a wide range of consumer-related nudges, supplying a kind of "green light" for officials. But many of the patterns are more specific, showing noteworthy and unanticipated differences across nations.

Public officials are inevitably interested in knowing whether their interventions will receive public approval, and if so, whether some groups will be more supportive than others. Our findings offer a more refined, and in some ways surprising, understanding of likely popular reactions to nudges. They also provide guidance about when targeted explanations and justifications may be both useful and important. 


\section{REFERENCES}

Agence France-Presse. 2016. Danish Town Says Pork Must Be Served at Public Institutions. The Guardian, January 19.

Ariely, Dan. 2008. Predictably Irrational: The Hidden Forces That Shape Our Decisions. New York: HarperCollins.

Arno, Anneliese, and Steve Thomas. 2016. The Efficacy of Nudge Theory Strategies in Influencing Adult Dietary Behaviour: A Systematic Review and Meta-Analysis. BMC Public Health, 16 (676-687).

Baxter, Michael. 2016. A Better Rim Weighting Algorithm. International Journal of Market Research (Forum), 58 (4): 621-634.

Bertrand, Marianne, and Adair Morse. 2011. Information Disclosure, Cognitive Biases and Payday Borrowing. Journal of Finance, 66 (6): 1865-1893.

Bleidorn, Wiebke, Ruben C. Arslan, Jaap J. A. Denissen, Peter J. Rentfrow, Jochen E. Gebauer, and Jeff Potter. 2016. Age and Gender Differences in Self-Esteem - a Cross-Cultural Window. Journal of Personality and Social Psychology, 111 (3): 396-410.

Bucher, Tamara, Clare Collins, Megan E. Rollo, Tracy A. McCaffrey, Nienke De Vlieger, Daphne Van der Bend, Helen Truby, and Federico J. A. Perez-Cueto. 2016. Nudging Consumers Towards Healthier Choices: A Systematic Review of Positional Influences on Food Choice. British Journal of Nutrition, 115 (2252-2263).

Chetty, Raj, John N. Friedman, Søren Leth-Petersen, Torben Heien Nielsen, and Tore Olsen. 2014. Active Vs. Passive Decisions and Crowd-out in Retirement Savings Accounts: Evidence from Denmark. The Quarterly Journal of Economics, 129 (3): 1141-1219.

Diepeveen, Stephanie, Tom Ling, Marc Suhrcke, Martin Roland, and Theresa M. Marteau. 2013. Public Acceptability of Government Intervention to Change Health-Related Behaviours: A Systematic Review and Narrative Synthesis. BMC Public Health, 13: 756-767.

Duflo, Esther, Rachel Glennerster, and Michael Kremer. 2007. Using Randomization in Development Economics Research: A Toolkit, Cepr Discussion Paper No. 6059. London: Centre for Economic Policy Research.

Egebark, Johan, and Mathias Ekström. 2016. Can Indifference Make the World Greener? Journal of Environmental Economics and Management, 76 (C): 1-13.

Felsen, Gidon, Noah Castelo, and Peter B. Reiner. 2013. Decisional Enhancement and Autonomy: Public Attitudes Towards Overt and Covert Nudges. Judgment and Decision Making, 8 (3): 202-213.

Fong, Geoffrey T., David Hammond, and Sara C. Hitchman. 2009. The Impact of Pictures on the Effectiveness of Tobacco Warnings. Bulletin of the World Health Organization, 87 (8): 640-643.

Giné, Xavier, Tomoko Harigaya, Dean Karlan, and Binh T. Nguyen. 2006. Evaluating Microfinance Program Innovation with Randomized Control Trials: An Example from Group Versus Individual Learning, Erd Technical Note Series, Economics and Research Department. Manila: Asian Development Bank.

Gregor, Shirley, and Brian Lee-Archer. 2016. The Digital Nudge in Social Security Administration. International Social Security Review, 69 (3-4): 63-83.

Gyrd-Hansen, Dorte, and Trine Kjær. 2015. Government Interventions to Aid Choice: Help to Self-Help Orpaternalism? Health Policy, 119: 874-881.

Hagman, William, David Andersson, Daniel Västfjäll, and Gustav Tinghög. 2015. Public Views on Policies Involving Nudges. Review of Philosophy and Psychology, 6 (3): 439-453. 
Haisley, Emily, Kevin G. Volpp, Thomas Pellathy, and George Loewenstein. 2012. The Impact of Alternative Incentive Schemes on Completion of Health Risk Assessments. American Journal of Health Promotion, 26 (3): 184-188.

Halpern, Scott D. 2016. Judging Nudges. The American Journal of Bioethics, 16 (5): 16-37. ILM. 2011. Ambition and Gender at Work. London: Institute of Leadership and Management. Jung, Janice Y., and Barbara A. Mellers. 2016. American Attitudes toward Nudges. Judgment and Decision making, 11 (1): 62-74.

Junghans, Astrid F., Tracy T. L. Cheung, and Denise D. T. de Ridder. 2015. Under Consumers' Scrutiny - an Investigation into Consumers' Attitudes and Concerns About Nudging in the Realm of Health Behavior. BMC Public Health, 15: 336 (13 pages).

Kahneman, Daniel. 2011. Thinking, Fast and Slow. New York City: Farrar, Straus and Giroux.

Laukkanen, Tommi. 2016. Consumer Adoption Versus Rejection Decisions in Seemingly Similar Service Innovations: The Case of the Internet and Mobile Banking. Journal of Business Research, 69 (7): 2432-2439.

List, John A., Sally Sadoff, and Mathis Wagner. 2010. So You Want to Run an Experiment, Now What? Some Simple Rules of Thumb for Optimal Experimental Design, Nber Working Paper Series, Working Paper 15701 Cambridge: National Bureau of Economic Research.

Lourenço, Joana Sousa, Emanuele Ciriolo, Sara Rafael Almeida, and Xavier Troussard. 2016. Behavioural Insights Applied to Policy: European Report 2016, Science for Policy Report by the Joint Research Centre. Brussels: European Commission.

Lucke, Jayne. 2013. Context Is All Important in Investigating Attitudes: Acceptability Depends on the Nature of the Nudge, Who Nudges, and Who Is Nudged. American Journal of Bioethics, 13 (6): 24-25.

Ly, Kim, Nina Mažar, Min Zhao, and Dilip Soman. 2013. A Practitioner's Guide to Nudging, Research Report Series: Behavioural Economics in Action. Toronto: Rotman School of Management, University of Toronto.

Marchiori, David R., Marieke A. Adriaanse, and Denise T. D. de Ridder. 2017. Unresolved Questions in Nudging Research: Putting the Psychology Back in Nudging. Social and Personality Psychology Compass, 17 (11): e12297 (13 p.).

Morris, Carol, James Kirwan, and Rhonwen Lally. 2014. Less Meat Initiatives: An Initial Exploration of a Diet-Focused Social Innovation in Transitions to a More Sustainable Regime of Meat Provisioning. Journal of Sociology of Agriculture and Food, 21 (2): 189208.

Mulderrig, Jane. 2017. Reframing Obesity: A Critical Discourse Analysis of the Uk's First Social Marketing Campaign. Critical Policy Studies, 11 (4): 455-476.

Nørnberg, Trine Riebeling, Louise Houlby, Laurits Rohden Skov, and Federico Jose Armando Peréz-Cueto. 2016. Choice Architecture Interventions for Increased Vegetable Intake and Behaviour Change in a School Setting: A Systematic Review. Perspectives in Public Health, 136 (3): 132-142.

OECD. 2014. Oecd Obesity Update 2014. Paris: OECD Directorate for Employment, Labour and Social Affairs.

OECD. 2015. Key Facts - Italy, Update 2014 (May 27), Obesity and the Economics of Prevention: Fit Not Fat. Paris.

OECD. 2017. Behavioural Insights and Public Policy: Lessons from around the World. Paris: OECD Publishing. 
Paloyo, Alfredo R., Arndt R. Reichert, Monika Reuss-Borst, and Harald Tauchmann. 2015. Who Responds to Financial Incentives for Weight Loss? Evidence from a Randomized Controlled Trial. Social Science \& Medicine, 145 (November): 44-52.

Petrescu, Dragos C., Gareth J. Hollands, Dominique-Laurent Couturier, Yin-Lam Ng, and Theresa M. Marteau. 2016. Public Acceptability in the Uk and USA of Nudging to Reduce Obesity: The Example of Reducing Sugar-Sweetened Beverages Consumption. PLoS ONE, 11 (6): 18 pages.

Ploug, Thomas, Soren Holm, and John Brodersen. 2012. To Nudge or Not to Nudge: Cancer Screening Programmes and the Limits of Libertarian Paternalism Journal of Epidemiology and Community Health, 66 (12): 1193-1196.

Public Health England. 2016. New Phe Data on Salt Consumption Levels: The National Diet and Nutrition Survey (Ndns) Shows That on Average Adults Are Eating 8 Grams of Salt Per Day, Obesity and Healthy Eating, Press Release (March 22). London.

Reisch, Lucia A., and Cass R. Sunstein. 2016. Do Europeans Like Nudges? Judgment and Decision Making, 11 (4): 310-325.

Reisch, Lucia A., Cass R. Sunstein, and Wencke Gwozdz. 2017. Beyond Carrots and Sticks: Europeans Support Health Nudges. Food Policy (Viewpoint), 69 (May): 1-10.

Rivers, Nicholas, Sarah Shenstone-Harris, and Nathan Young. 2017. Using Nudges to Reduce Waste? The Case of Toronto's Plastic Bag Levy. Journal of Environmental Management, 188: 153-162.

Sudman, Seymour, and Brian Wansink. 2002. Consumer Panels. 2 ed: South-Western Educational Publications.

Sunstein, Cass R. 2016. People Prefer System 2 Nudges (Kind of). Duke Law Journal, 66: 121168.

Sunstein, Cass R. Forthcoming. Do People Like Nudges? Administrative Law Review.

Sunstein, Cass R., Lucia A. Reisch, and Julius Rauber. 2017. A Worldwide Consensus on Nudging? Not Quite, but Almost. Regulation and Governance, doi:10.1111/rego.12161.

Tannenbaum, David, Craig R. Fox, and Todd Rogers. 2017. On the Misplaced Politics of Behavioural Policy Interventions. Nature Human Behaviour (Letters), 1 (0130): 1-7.

Thaler, Richard H., and Cass R. Sunstein. 2008. Nudge: Improving Decisions About Health, Wealth, and Happiness. New Haven: Yale University Press.

The Behavioral Insights Team. 2016. Update Report 2015-16. London.

The World Bank. 2015. Mind, Society, and Behavior, A World Bank Group Flagship Report. Washington: International Bank for Reconstruction and Development, The World Bank.

Venkatesh, Viswanath, Michael G. Morris, and Phillip L. Ackerman. 2000. A Longitudinal Field Investigation of Gender Differences in Individual Technology Adoption DecisionMaking Processes. Organizational Behavior and Human Decision Processes, 83 (1): 3360.

Wilson, Amy L., Elizabeth Buckley, Jonathan D. Buckley, and Svetlana Bogomolova. 2016. Nudging Healthier Food and Beverage Choices through Salience and Priming. Evidence from a Systematic Review. Food Quality and Preference, 51 (July): 47-64.

Woersdorfer, Julia Sophie, and Wolfhard Kaus. 2011. Will Nonowners Follow Pioneer Consumers in the Adoption of Solar Thermal Systems? Empirical Evidence for Northwestern Germany. Ecological Economics, 70 (12): 2282-2291.

Yeung, Karen. 2017. 'Hypernudge': Big Data as a Mode of Regulation by Design. Information Communication and Society, 20 (1): 118-136. 


\section{TABLES}

TABLE 1

Description of Nudges and Approval Rates by Country

Nudge

chain restaurants (such as McDonald's and Burger King).

2. "Traffic lights": The federal government requires a "traffic lights" system for food, by which healthy foods would be sold with a small green label, unhealthy foods with a small red label, and foods that are neither especially healthy nor especially unhealthy with a small yellow label.

3. "Encouragement green energy": The federal government encourages (without requiring) electricity providers to adopt a system in which consumers would be automatically enrolled in a "green"

(environmentally friendly) energy supplier, but could opt out if they wished.

4. "Organ donor choice": A state law requiring people to say, when they obtain their drivers' license, whether they want to be organ donors.

5. "Healthy food placement": A state law requires all large grocery stores to place their most healthy foods in a prominent, visible location.

6. "Distracted driving": To reduce deaths and injuries associated with distracted driving, the national government adopts a public education campaign, consisting of vivid and sometimes graphic stories and images, designed to discourage people from texting, emailing, or talking on their cellphones while driving.

7. "Childhood obesity": To reduce childhood obesity, the national government adopts a public education campaign, consisting of information that parents can use to make healthier choices for their children.

8. "Subliminal advertisements": The federal government requires movie theaters to provide subliminal advertisements (that is, advertisements that go by so quickly that people are not consciously aware of them) designed to discourage people from smoking and overeating.

9. "Carbon emissions charge": The federal government requires airlines to charge people, with their airline tickets, a specific amount to offset their carbon emissions (about 10 EUR per ticket); under the program, people can opt out of the payment if they explicitly say that they do not want to pay it.

10. "High levels of salt": The federal government requires labels on products that have unusually high levels of salt, as in: This product has been found to contain unusually high levels of salt, which may be harmful to your health.

11. "Red cross": The federal government assumes, on tax returns, that people want to donate 50 EUR to the Red Cross (or to another good cause) subject to opt out if people explicitly say that they do not want to make that donation.

12. "Smoking and overeating": The federal government requires movie theaters to run public education messages designed to discourage people from smoking and overeating.

13. "Mandate green energy": The federal government requires large electricity providers to adopt a system in which consumers would be automatically enrolled in a "green" (environmentally friendly) energy supplier, but could opt out if they wished.

14. "Sweet-free cashier zone": To halt the rising obesity problem, the

$\begin{array}{cccccc}\text { System } & \text { Type } & \text { DK } & \text { HU } & \text { UK } & \text { IT } \\ 2 & 2 & 63 \% & 73 \% & 85 \% & 87 \% \\ & & & & & \\ 2 & 2 & 54 \% & 62 \% & 85 \% & 78 \%\end{array}$

$\begin{array}{llllll}1 & 3 & 64 \% & 72 \% & 65 \% & 75 \%\end{array}$

$2 \quad 3 \quad 63 \% \quad 54 \% \quad 72 \% \quad 73 \%$

$\begin{array}{llllll}1 & 3 & 48 \% & 61 \% & 74 \% & 77 \%\end{array}$

$\begin{array}{llllll}2 & 1 & 80 \% & 77 \% & 88 \% & 87 \%\end{array}$

$\begin{array}{llllll}2 & 1 & 83 \% & 80 \% & 88 \% & 89 \%\end{array}$

$\begin{array}{llllll}1 & 5 & 24 \% & 39 \% & 49 \% & 55 \%\end{array}$

$\begin{array}{llllll}1 & 3 & 36 \% & 20 \% & 46 \% & 41 \%\end{array}$

$\begin{array}{llllll}1 & 3 & 14 \% & 38 \% & 26 \% & 47 \%\end{array}$

$\begin{array}{llllll}2 & 1 & 36 \% & 42 \% & 67 \% & 78 \%\end{array}$

$\begin{array}{llllll}1 & 3 & 57 \% & 66 \% & 65 \% & 74 \%\end{array}$

$\begin{array}{llllll}1 & 4 & 57 \% & 44 \% & 81 \% & 55 \%\end{array}$ 
federal government requires large supermarket chains to keep cashier areas free of sweets.

15. "Meat-free day": For reasons of public health and climate protection, the federal government requires canteens in public institutions (schools, public administrations and similar) to have one meat-free day per week.

$\begin{array}{lllllll}1 & 4 & 30 \% & 47 \% & 51 \% & 74 \%\end{array}$

Note: Types reflect increasing intrusiveness ranging from $1=$ government information campaigns, $2=$ governmentally mandated information mandates, $3=$ default rules, $4=$ choice architectures, to $5=$ subliminal advertisement. 
TABLE 2

Coefficients of OLS and Binary Logistic Regressions of the Danes' Sample of Nudge Approval on Individual, Household, and Geographic Variables, $N=834$, Weighted

\begin{tabular}{|c|c|c|c|c|c|c|c|c|}
\hline & $\begin{array}{l}\text { Sum of } 15 \\
\text { nudges } \\
\text { Std. Beta } \\
\end{array}$ & $\begin{array}{l}\text { System 1, } \\
\text { binary } \\
\operatorname{Exp}(\mathrm{B})\end{array}$ & $\begin{array}{l}\text { System } 2, \\
\text { binary } \\
\operatorname{Exp}(B)\end{array}$ & $\begin{array}{l}\text { Type 1, } \\
\text { binary } \\
\operatorname{Exp}(\mathrm{B})\end{array}$ & $\begin{array}{l}\text { Type } 2, \\
\text { binary } \\
\operatorname{Exp}(\mathrm{B})\end{array}$ & $\begin{array}{l}\text { Type } 3, \\
\text { binary } \\
\operatorname{Exp}(B)\end{array}$ & $\begin{array}{l}\text { Type } 4, \\
\text { binary } \\
\operatorname{Exp}(B)\end{array}$ & $\begin{array}{l}\text { Type } 5, \\
\text { binary } \\
\operatorname{Exp}(B)\end{array}$ \\
\hline Age, 30-39 yrs. & 0.039 & 0.714 & $2.134 *$ & 1.282 & 1.598 & 1.096 & 0.882 & $0.454 *$ \\
\hline Age, $40-49$ yrs. & -0.062 & $0.336 * * *$ & 1.416 & 1.171 & 1.291 & 0.808 & $0.539+$ & $0.264 * * *$ \\
\hline Age, $50-59$ yrs. & 0.036 & 0.977 & 1.248 & 1.647 & 1.454 & 1.423 & 0.891 & $0.526^{*}$ \\
\hline Age, 60-69 yrs. & 0.020 & 0.855 & 1.088 & 1.299 & 1.253 & 1.276 & 0.902 & 0.806 \\
\hline Age, 70 and older & -0.070 & $0.454 *$ & 0.815 & 1.223 & 0.748 & 0.659 & 0.666 & 0.732 \\
\hline Male & 0.004 & 1.120 & 1.030 & 1.120 & 1.111 & 0.974 & 0.956 & $1.530 *$ \\
\hline Household size & 0.015 & 1.170 & 0.838 & $0.738 *$ & 0.975 & 1.054 & 1.156 & 0.966 \\
\hline Number children & 0.022 & 1.061 & 1.290 & 1.279 & 1.021 & 0.928 & 1.026 & $1.485^{*}$ \\
\hline High school & -0.028 & 0.618 & $0.502 *$ & 1.094 & 0.886 & 1.091 & 0.982 & $0.422 *$ \\
\hline Lower elementary business school & 0.037 & 1.133 & 0.785 & 1.281 & 0.913 & 1.388 & 1.314 & 1.122 \\
\hline Elementary business school & -0.021 & 0.783 & 0.936 & 0.972 & 1.009 & 1.022 & 0.832 & $0.581+$ \\
\hline Short graduate & -0.058 & 0.865 & 0.574 & 0.776 & 0.825 & 1.08 & 0.599 & 0.565 \\
\hline Medium graduate /bachelor & 0.062 & 1.019 & 1.263 & 1.548 & 1.364 & 1.503 & $1.852 *$ & $0.366 * * *$ \\
\hline Longer graduate /university & -0.065 & 0.896 & 0.659 & 0.744 & 0.589 & 1.016 & $2.075+$ & $0.225 * * *$ \\
\hline \multicolumn{9}{|l|}{ Annual gross household income: } \\
\hline 200,000-299,999 DKK & $-0.135 * *$ & $0.526 *$ & $0.457 *$ & 0.658 & 0.728 & $0.372 * * *$ & 0.692 & 0.836 \\
\hline 300,000-399,999 DKK & $-0.125^{*}$ & $0.431 * *$ & $0.546+$ & 0.832 & 0.675 & $0.441 * *$ & 0.617 & 1.214 \\
\hline 400,000-499,999 DKK & $-0.097 *$ & $0.367 * *$ & 0.748 & 0.919 & $0.571+$ & $0.422 * *$ & 0.613 & 1.198 \\
\hline 500,000-599,999 DKK & $-0.088+$ & $0.456^{*}$ & 0.533 & 0.810 & 0.578 & $0.407 *$ & $0.429 *$ & 1.383 \\
\hline 600,000-699,999 DKK & $-0.090+$ & $0.473 *$ & 0.750 & 1.423 & 0.760 & $0.441 *$ & 0.707 & 1.365 \\
\hline 700,000-799,999 DKK & $-0.152 * *$ & $0.240 * *$ & $0.252 * *$ & $0.385^{*}$ & $0.343 * *$ & $0.362 * *$ & $0.360 *$ & 0.869 \\
\hline $800,000-899,999$ DKK & $-0.118 *$ & $0.390 *$ & $0.316 * *$ & 0.626 & $0.394 *$ & $0.416^{*}$ & 0.484 & 1.239 \\
\hline $900,000 \mathrm{DKK}$ and more & $-0.085+$ & $0.126 * * *$ & 0.707 & 0.929 & 0.801 & $0.187 * * *$ & $0.281 *$ & 1.644 \\
\hline Region Zealand & -0.017 & 1.058 & 0.879 & 0.764 & 1.037 & 0.810 & 1.274 & $1.632+$ \\
\hline Region South Denmark & -0.054 & 0.798 & 1.073 & 0.888 & 0.872 & $0.695+$ & 0.673 & 1.078 \\
\hline Region Mid Jutland & 0.023 & 1.033 & 1.262 & 0.956 & 1.246 & 0.86 & 1.212 & 1.455 \\
\hline Region North Jutland & 0.015 & 1.337 & 1.000 & 0.882 & 1.003 & 1.208 & 0.77 & 1.58 \\
\hline Constant & & 0.882 & $5.419 * * *$ & 4.932 & 2.173 & 1.054 & 0.331 & 0.474 \\
\hline $\mathrm{R}^{2} / \mathrm{adj} . \mathrm{R}^{2} ; \operatorname{Cox} \&$ & $0.052 / 0.021$ & $0.069 / 0.098$ & $0.055 / 0.079$ & $0.035 / 0.052$ & $0.038 / 0.052$ & $0.051 / 0.071$ & $0.053 / 0.082$ & $0.074 / 0.11$ \\
\hline Snell/Nagelkerke $\mathrm{R}^{2}$ & & & & & & & & 0 \\
\hline $\mathrm{F}$; Chi-square & $1.689 *$ & $59.326 * * *$ & $47.376 * *$ & 29.999 & 32.401 & $44.046^{*}$ & $45.578 *$ & $64.211 * * *$ \\
\hline
\end{tabular}

Baseline categories: Age: up to 29 yrs.; education: primary/elementary school; annual gross household income: under 199,999 DKK; region: capital region of Copenhagen (\%). Types reflect increasing intrusiveness ranging from 1=government information campaigns, $2=$ governmentally mandated information mandates, $3=$ default rules, $4=$ choice architectures, to $5=$ subliminal advertisement. 
TABLE 3

Coefficients of OLS and Binary Logistic Regressions of the Hungarian Sample of Nudge Approval on Individual, Household, and Geographic Variables, $N=852$, Weighted

\begin{tabular}{|c|c|c|c|c|c|c|c|c|}
\hline Variables & $\begin{array}{l}\text { Sum of } 15 \\
\text { nudges } \\
\text { Std. Beta }\end{array}$ & $\begin{array}{l}\text { System } 1, \\
\text { binary } \\
\operatorname{Exp}(B)\end{array}$ & $\begin{array}{l}\text { System } 2, \\
\text { binary } \\
\operatorname{Exp}(B)\end{array}$ & $\begin{array}{l}\text { Type } 1, \\
\text { binary } \\
\operatorname{Exp}(B)\end{array}$ & $\begin{array}{l}\text { Type } 2, \\
\text { binary } \\
\operatorname{Exp}(\mathrm{B})\end{array}$ & $\begin{array}{l}\text { Type } 3, \\
\text { binary } \\
\operatorname{Exp}(\mathrm{B})\end{array}$ & $\begin{array}{l}\text { Type } 4, \\
\text { binary } \\
\operatorname{Exp}(B)\end{array}$ & $\begin{array}{l}\text { Type } 5, \\
\text { binary } \\
\operatorname{Exp}(B)\end{array}$ \\
\hline Age, 30-39 yrs. & 0.032 & 1.525 & 1.089 & $1.716^{*}$ & $0.674+$ & $1.541 *$ & $1.851^{*}$ & 1.132 \\
\hline Age, $40-49$ yrs. & -0.064 & 0.842 & $0.616^{*}$ & 0.899 & 0.694 & 0.752 & 1.273 & 0.944 \\
\hline Age, 50-59 yrs. & 0.014 & 1.215 & 0.839 & 1.457 & 0.853 & 1.164 & $1.669 *$ & 1.277 \\
\hline Age, $60-69$ yrs. & 0.045 & $1.682 *$ & 0.883 & $2.296 * *$ & 0.735 & 1.297 & $1.629+$ & 1.330 \\
\hline Male & $-0.072 *$ & 0.795 & $0.631 * *$ & 0.780 & 0.800 & 0.858 & $0.692 *$ & 0.979 \\
\hline Secondary vocational, engineering & -0.049 & & & & & & & \\
\hline or grammar school with GCSE & & 0.811 & 1.001 & 1.087 & 0.829 & $0.694+$ & 0.946 & 0.926 \\
\hline Completed college or university & -0.082 & 0.932 & 0.897 & 1.063 & 0.844 & $0.644 *$ & 0.955 & 0.773 \\
\hline Monthly household income: & & & & & & & & \\
\hline HUF $80,001-140,000$ & 0.022 & 0.919 & 1.140 & 1.380 & 1.262 & 1.096 & 0.963 & 1.082 \\
\hline HUF $140,001-200,000$ & 0.026 & 0.944 & 0.978 & 1.102 & 1.441 & 1.199 & 1.313 & 1.193 \\
\hline HUF $200,001-260,000$ & $-0.111+$ & $0.416 * *$ & 0.769 & 0.976 & 0.892 & 0.608 & $0.523+$ & 0.885 \\
\hline HUF $260,001-320,000$ & 0.024 & 0.618 & 1.013 & 1.613 & 0.990 & 1.135 & 0.782 & 1.131 \\
\hline HUF $320,001-380,000$ & -0.003 & 0.576 & 1.001 & 1.084 & 0.922 & 0.744 & 1.132 & 1.516 \\
\hline HUF 380,001 and higher & -0.080 & $0.366 * *$ & 0.861 & 1.063 & 0.908 & 0.565 & 0.601 & 0.682 \\
\hline Social class high & 0.079 & 1.520 & 1.138 & 0.852 & 1.592 & $1.763^{*}$ & 1.163 & 1.031 \\
\hline Social class mid & 0.080 & 1.209 & 1.392 & 0.916 & $1.656^{*}$ & $1.602 *$ & 0.826 & 0.877 \\
\hline Urban residence & $0.195^{*}$ & 1.806 & $3.011 *$ & 1.392 & $3.926 * *$ & 1.477 & 1.036 & 1.655 \\
\hline Community size, $1-1,000$ & 0.079 & 1.805 & $3.108+$ & 1.670 & $3.250+$ & 1.680 & 0.669 & 2.158 \\
\hline Community size, $1,001-2,000$ & $0.186 * *$ & $3.390 *$ & $3.336 *$ & 1.424 & $5.803 * *$ & 2.022 & 1.086 & $3.262 *$ \\
\hline Community size, $2,001-5,000$ & $0.136^{*}$ & $2.306 *$ & 1.954 & 0.946 & $3.552 *$ & $2.020+$ & 0.859 & $2.745^{*}$ \\
\hline Community size, $5,001-10,000$ & 0.067 & 1.620 & 1.533 & 1.786 & 1.737 & $2.026^{*}$ & 1.105 & $1.780+$ \\
\hline Community size, $10,001-20,000$ & 0.002 & 1.524 & 0.927 & 0.894 & 1.012 & 1.122 & 1.309 & $1.648+$ \\
\hline Community size $20,001-50,000$ & 0.008 & 1.438 & 0.960 & 0.935 & 1.028 & 1.394 & 1.041 & 1.177 \\
\hline Community size, over 50,000 & 0.001 & 0.954 & 0.819 & 0.820 & 1.134 & 0.931 & 0.749 & 1.315 \\
\hline Constant & & $0.365+$ & 1.151 & 1.570 & 0.579 & 0.440 & 0.406 & $0.282 *$ \\
\hline $\begin{array}{l}\mathrm{R}^{2} / \text { adj. } \mathrm{R}^{2} ; \text { Cox \& Snell/Nagelkerke } \\
\mathrm{R}^{2}\end{array}$ & $0.057 / 0.031$ & $0.058 / 0.079$ & $0.037 / 0.054$ & $0.037 / 0.054$ & $0.035 / 0.050$ & $0.053 / 0.071$ & $0.043 / 0.062$ & $0.033 / 0.045$ \\
\hline F; Chi-square statistics & $2.189 * *$ & $51.279 * *$ & $32.455+$ & $32.231+$ & 30.146 & $46.374 * *$ & $37.486^{*}$ & 28.909 \\
\hline
\end{tabular}

Note: $+<0.10, *<0.05, * *<0.01, * * *<0.001$

Baseline categories: Age: up to 29 yrs.; education: 8 yrs. of elementary or less, finished secondary technical institute, vocational school; monthly household income: under HUF 80,000; social class: low; community size: Budapest. Types reflect increasing intrusiveness ranging from 1=government information campaigns, 2=governmentally mandated information mandates, $3=$ default rules, $4=$ choice architectures, to $5=$ subliminal advertisement. 
TABLE 4

Coefficients of OLS and Binary Logistic Regressions of the United Kingdom Sample of Nudge Approval on Individual, Household, and Geographic Variables, $N=1,805$, Weighted

\begin{tabular}{|c|c|c|c|c|c|c|c|c|}
\hline & $\begin{array}{l}\text { Sum of } 15 \\
\text { nudges } \\
\text { Std. Beta }\end{array}$ & $\begin{array}{l}\text { System } 1, \\
\text { binary } \\
\operatorname{Exp}(B)\end{array}$ & $\begin{array}{l}\text { System } 2, \\
\text { binary } \\
\operatorname{Exp}(B)\end{array}$ & $\begin{array}{l}\text { Type } 1, \\
\text { binary } \\
\operatorname{Exp}(\mathrm{B})\end{array}$ & $\begin{array}{l}\text { Type } 2, \\
\text { binary } \\
\operatorname{Exp}(\mathrm{B})\end{array}$ & $\begin{array}{l}\text { Type } 3, \\
\text { binary } \\
\operatorname{Exp}(\mathrm{B})\end{array}$ & $\begin{array}{l}\text { Type } 4, \\
\text { binary } \\
\operatorname{Exp}(B)\end{array}$ & $\begin{array}{l}\text { Type } 5, \\
\text { binary } \\
\operatorname{Exp}(B)\end{array}$ \\
\hline Age, 30-39 yrs. & 0.012 & 0.759 & $2.147 * *$ & 1.254 & $2.153 * *$ & 0.797 & 0.905 & $0.606 * *$ \\
\hline Age, $40-49$ yrs. & -0.026 & $0.615^{* *}$ & $2.305 * *$ & $2.067 * *$ & $1.781 *$ & $0.667 *$ & 0.785 & $0.498 * * *$ \\
\hline Age, $50-59$ yrs. & -0.038 & $0.539 * *$ & $2.432 * *$ & $1.800 *$ & $2.497 * *$ & $0.502 * * *$ & $0.644 *$ & $0.452 * * *$ \\
\hline Age, $60-69$ yrs. & $-0.075^{*}$ & $0.582 * *$ & 1.371 & 1.539 & 1.310 & $0.559 * *$ & $0.582 * *$ & $0.532 * *$ \\
\hline Age, 70 and older & -0.053 & $0.574 *$ & 1.387 & 1.624 & 1.544 & $0.537 * *$ & $0.626 *$ & $0.562 *$ \\
\hline Male & $-0.122 * * *$ & $0.651 * * *$ & $0.616 * *$ & 0.876 & $0.522 * * *$ & $0.692 * * *$ & $0.659 * * *$ & $0.722 * *$ \\
\hline Married/living with partner & 0.043 & 1.143 & 1.081 & 0.859 & $1.473+$ & 1.145 & $1.359 *$ & 1.202 \\
\hline Divorced/separated/widowed & 0.020 & 1.095 & $2.191 *$ & 0.882 & $1.801+$ & 0.929 & 1.225 & 1.147 \\
\hline $\begin{array}{l}\text { University degree or equivalent } \\
\text { prof. qualification, etc. }\end{array}$ & -0.023 & 0.865 & 0.992 & 1.226 & 0.797 & 1.000 & 1.050 & 0.873 \\
\hline $\begin{array}{l}\text { Higher university degree, } \\
\text { doctorate, etc. }\end{array}$ & 0.019 & 1.091 & 1.006 & 0.715 & 0.878 & 1.192 & $1.352+$ & 1.179 \\
\hline Employment, full-time & 0.004 & 1.241 & 0.725 & $0.631 *$ & 0.849 & 1.109 & 0.928 & $1.557 * *$ \\
\hline Employment, part-time & -0.016 & 1.234 & 0.620 & 0.665 & 0.860 & 1.107 & 0.842 & 1.312 \\
\hline Annual gross household income: & & & & & & & & \\
\hline GBP 14,001-21,000 & 0.043 & 1.405 & 1.557 & 1.437 & $1.653+$ & 1.218 & 0.885 & $1.490 *$ \\
\hline GBP 21,001-28,000 & $0.081 *$ & 1.544 & $2.524 * *$ & $1.868 *$ & 1.513 & $1.605 *$ & 0.931 & $1.463 *$ \\
\hline GBP $28,001-34,000$ & $0.069 *$ & 1.496 & $2.026 *$ & 1.291 & $1.830+$ & $1.414+$ & 1.064 & $1.477+$ \\
\hline GBP 34,001-41,000 & 0.031 & 1.488 & 1.320 & 1.177 & 1.287 & 1.207 & 0.718 & 1.311 \\
\hline GBP 41,001-48,000 & 0.049 & 1.961 & $2.484 *$ & 1.322 & 1.624 & $1.697 *$ & 0.857 & 1.222 \\
\hline GBP 48,001-55,000 & 0.034 & 1.491 & 1.891 & 1.154 & 1.739 & $1.567+$ & 0.780 & 1.522 \\
\hline GBP 55,001-69,000 & 0.053 & 1.733 & $2.809 *$ & 1.642 & $2.945^{*}$ & $1.716^{*}$ & 1.067 & 1.214 \\
\hline GBP 69,001 or more & 0.025 & 1.665 & 1.751 & 0.963 & 1.630 & $1.513+$ & 0.749 & 1.371 \\
\hline Region North East & -0.013 & 0.922 & 1.060 & 0.681 & 1.130 & 0.916 & 0.842 & 0.930 \\
\hline Region North West & -0.039 & 0.793 & 0.640 & 0.693 & $0.544 *$ & 0.785 & 1.095 & 0.810 \\
\hline Region Midlands & $-0.065^{*}$ & 0.676 & 0.796 & $0.517 * *$ & $0.628+$ & $0.745+$ & 0.801 & $0.748+$ \\
\hline Region East of England, South & & & & & & & & \\
\hline West & -0.044 & 0.872 & 0.809 & $0.448 * * *$ & 1.122 & 0.820 & $0.695 *$ & 0.946 \\
\hline Region Wales & 0.013 & 1.021 & 0.680 & 0.807 & 0.610 & 1.397 & 1.014 & 0.959 \\
\hline Region Scotland & -0.014 & 0.855 & 0.877 & 0.652 & 0.722 & 1.020 & 0.850 & 0.923 \\
\hline Social class A & 0.010 & 0.867 & 1.294 & $2.412 *$ & 0.872 & 0.827 & 0.923 & 1.068 \\
\hline Social class B & -0.032 & 0.624 & 1.006 & 1.385 & 1.228 & $0.666+$ & 0.832 & 0.702 \\
\hline Social class $\mathrm{C}$ & 0.000 & 0.803 & 1.549 & 1.496 & 1.517 & 0.799 & 0.982 & 0.799 \\
\hline Social class D & -0.023 & 0.877 & 0.895 & 0.986 & 1.300 & 0.769 & 0.893 & 0.981 \\
\hline Constant & & 1.745 & $4.855 * * *$ & $6.242 * * *$ & 4.336 *** & $1.856^{* *}$ & $1.440+$ & 1.394 \\
\hline
\end{tabular}


Baseline categories: Age: up to 29 yrs.; marital status: single; education: secondary school, high school, NVQ levels 1 to 3 , etc., still in full-time education, no formal education; employment: none; annual gross household income: up to GBP 14,000; region: south east; social class: E. Types reflect increasing

intrusiveness ranging from $1=$ government information campaigns, $2=$ governmentally mandated information mandates, $3=$ default rules, $4=$ choice architectures, to $5=$ subliminal advertisement. 
TABLE 5

Coefficients of OLS and Binary Logistic Regressions of the Italian Sample of Nudge Approval on Individual, Household, and Geographic Variables, $N=741$, Stratified

\begin{tabular}{|c|c|c|c|c|c|c|c|c|}
\hline Variables & $\begin{array}{l}\text { Mean of } 15 \\
\text { nudges } \\
\text { Std. Beta }\end{array}$ & $\begin{array}{l}\text { System 1, } \\
\text { binary } \\
\operatorname{Exp}(B) \\
\end{array}$ & $\begin{array}{l}\text { System } 2, \\
\text { binary } \\
\operatorname{Exp}(B)\end{array}$ & $\begin{array}{l}\text { Type } 1, \\
\text { binary } \\
\operatorname{Exp}(\mathrm{B})\end{array}$ & $\begin{array}{l}\text { Type } 2, \\
\text { binary } \\
\operatorname{Exp}(B)\end{array}$ & $\begin{array}{l}\text { Type } 3, \\
\text { binary } \\
\operatorname{Exp}(B)\end{array}$ & $\begin{array}{l}\text { Type } 4, \\
\text { binary } \\
\operatorname{Exp}(B)\end{array}$ & $\begin{array}{l}\text { Type } 5, \\
\text { binary } \\
\operatorname{Exp}(B)\end{array}$ \\
\hline Age, 30-39 yrs. & -0.034 & 0.690 & 0.867 & 1.118 & 0.647 & 0.905 & 1.325 & 0.952 \\
\hline Age, $40-49$ yrs. & -0.001 & 0.759 & 1.574 & 1.791 & 0.786 & 0.893 & 1.261 & 0.787 \\
\hline Age, 50-59 yrs. & 0.090 & 0.995 & 1.418 & 1.820 & 1.031 & 1.140 & $2.283 * *$ & 1.457 \\
\hline Age, 60-69 yrs. & 0.027 & 0.947 & 1.541 & 1.814 & 0.770 & 0.876 & 1.571 & 1.115 \\
\hline Male & $-0.074+$ & 0.798 & 0.842 & 1.048 & 0.909 & 0.793 & 0.829 & $0.624 * *$ \\
\hline Household size & -0.055 & 0.945 & 0.855 & 0.926 & 0.957 & 0.945 & 0.886 & 0.993 \\
\hline Marital status, married/living w/partner & -0.042 & 0.865 & 0.809 & 0.721 & 0.894 & 0.896 & 0.814 & 1.001 \\
\hline Marital status, divorced/separated/wid. & -0.050 & 0.710 & 0.791 & 0.910 & 0.941 & 0.648 & 0.734 & 0.673 \\
\hline Children & 0.010 & 1.020 & 0.946 & 0.784 & 1.154 & 0.849 & 1.212 & 1.165 \\
\hline Higher education & -0.042 & 0.816 & 1.309 & 0.920 & 0.805 & 0.975 & 0.873 & $0.500 * *$ \\
\hline University degree & -0.040 & 0.691 & 1.588 & 1.020 & 0.793 & 1.074 & 0.882 & $0.427 * *$ \\
\hline Profession, white collar, blue collar & 0.069 & $1.493+$ & 0.957 & 1.008 & 1.455 & 1.200 & 1.388 & $1.552 *$ \\
\hline Profession, student & 0.015 & 1.086 & 1.016 & 1.152 & 0.592 & 1.253 & 1.427 & 1.316 \\
\hline Profession, housewife & 0.019 & 1.003 & 2.048 & 2.272 & 1.846 & 1.135 & 1.249 & 0.692 \\
\hline Profession, retired & 0.011 & 1.246 & 1.630 & 1.288 & 3.614 & 1.384 & 1.086 & 0.942 \\
\hline $\begin{array}{l}\text { Profession, not working, other profession } \\
\text { Monthly net household income: }\end{array}$ & $0.104 *$ & $1.943 *$ & $2.607+$ & 1.438 & $2.002+$ & $1.640+$ & $1.979 *$ & 1.067 \\
\hline EUR 1,060-1,264 & 0.050 & 1.185 & 1.543 & 1.480 & 0.999 & 1.256 & 1.039 & 1.414 \\
\hline EUR 1,265-1,549 & 0.075 & 1.505 & 1.954 & 1.690 & 1.274 & $1.635+$ & 0.906 & 1.515 \\
\hline EUR 1,550-1,939 & $0.135 * *$ & 1.611 & $3.667 * *$ & $3.457 * *$ & 1.623 & $1.964 *$ & 1.121 & $1.615+$ \\
\hline EUR 1,940-2,454 & $0.130 *$ & $1.784 *$ & $3.245 *$ & $3.481 * *$ & 1.118 & 1.356 & 1.337 & 1.464 \\
\hline EUR 2,455 plus & 0.084 & 1.237 & $3.896 * *$ & $2.202+$ & $2.259+$ & 0.987 & 0.954 & 1.500 \\
\hline Region North West & $-0.133 * *$ & 0.752 & $0.409 *$ & $0.533+$ & $0.381 * *$ & 0.744 & $0.685+$ & 0.785 \\
\hline Region North East & -0.065 & 0.902 & 0.962 & 0.950 & 0.729 & 0.722 & 0.770 & 0.786 \\
\hline Region South & -0.023 & 1.148 & 0.816 & 1.271 & $0.470 *$ & 0.876 & 1.086 & 1.206 \\
\hline Region Islands & 0.002 & 1.014 & 1.264 & 1.282 & 0.908 & 1.224 & 0.908 & 0.840 \\
\hline Constant & & 1.967 & $6.504 *$ & $4.615^{*}$ & $10.914 * *$ & 1.944 & 0.975 & 1.884 \\
\hline $\mathrm{R}^{2} /$ adj. $\mathrm{R}^{2} ;$ Cox \& Snell/Nagelkerke $\mathrm{R}^{2}$ & $0.053 / 0.020$ & $0.031 / 0.042$ & $0.045 / 0.096$ & $0.040 / 0.079$ & $0.046 / 0.082$ & $0.030 / 0.041$ & $0.045 / 0.061$ & $0.045 / 0.061$ \\
\hline F; Chi-square statistics & $1.610^{*}$ & 23.474 & 34.333 & 30.275 & $34.923+$ & 22.503 & $34.411+$ & 34.298 \\
\hline
\end{tabular}
Note: $+<0.10, *<0.05, * *<0.01, * * *<0.001$

Baseline categories: Age: up to 29 yrs.; marital status, single; education: pre-primary, primary, secondary; profession: self-employed, farmer, fisherman; monthly net household income: up to EUR 1,059; region: center. Types reflect increasing intrusiveness ranging from 1=government information campaigns,

$2=$ governmentally mandated information mandates, $3=$ default rules, $4=$ choice architectures, to $5=$ subliminal advertisement. 


\section{ONLINE APPENDIX}

APPENDIX TABLE 1:

Descriptive Statistics of Individual, Household, and Geographic Variables Used in the Analysis of the Danes' Sample, Mean (SD) or Percent, Weighted

\begin{tabular}{|c|c|}
\hline Variables & Mean $(\mathrm{SD})$ or $\%$ \\
\hline Number of approved nudges $(0-15)$ & $7.79(3.391)$ \\
\hline High approval of System 1 nudges (\%) & 29.26 \\
\hline High approval of System 2 nudges (\%) & 71.57 \\
\hline High approval of Type 1 info campaign nudges (\%) & 74.70 \\
\hline High approval of Type 2 info mandate nudges (\%) & 63.51 \\
\hline High approval of Type 3 default rule nudges (\%) & 36.04 \\
\hline High approval of Type 4 choice architecture nudges (\%) & 21.84 \\
\hline High approval of Type 5 subliminal-advertisement stimuli (\%) & 24.45 \\
\hline $\operatorname{Age}^{\text {a) }}$ & $48.28(16.928)$ \\
\hline Age, up to 29 yrs. (\%) & 21.08 \\
\hline Age, $30-39$ yrs. (\%) & 12.06 \\
\hline Age, $40-49$ yrs. $(\%)$ & 17.47 \\
\hline Age, 50-59 yrs. (\%) & 18.20 \\
\hline Age, $60-69$ yrs. (\%) & 19.83 \\
\hline Age, 70 and older (\%) & 11.36 \\
\hline Male (\%) & 51.85 \\
\hline Household size (1-6) & $2.23(1.156)$ \\
\hline Number children $(0-4)$ & $0.47(0.863)$ \\
\hline Education, primary/elementary school (\%) & 14.71 \\
\hline Education, high school (\%) & 10.99 \\
\hline Education, lower elementary business school (\%) & 9.81 \\
\hline Education, elementary business school (\%) & 20.18 \\
\hline Education, short graduate $(\%)$ & 8.01 \\
\hline Education, medium graduate /bachelor (\%) & 26.57 \\
\hline Education, longer graduate /university (\%) & 9.30 \\
\hline Annual gross household income (DKK) ${ }^{\text {b) }}$ & $462,261(253,383)$ \\
\hline Under 199,999 DKK (\%) & 15.33 \\
\hline 200,000-299,999 DKK (\%) & 16.16 \\
\hline 300,000-399,999 DKK (\%) & 17.35 \\
\hline 400,000-499,999 DKK (\%) & 12.05 \\
\hline $500,000-599,999$ DKK $(\%)$ & 9.06 \\
\hline 600,000-699,999 DKK (\%) & 9.93 \\
\hline 700,000-799,999 DKK (\%) & 6.75 \\
\hline 800,000-899,999 DKK (\%) & 6.95 \\
\hline Above 900,000 DKK (\%) & 6.43 \\
\hline Region Capital (\%) & 31.62 \\
\hline Region Zealand (\%) & 14.08 \\
\hline Region South Denmark (\%) & 20.93 \\
\hline Region Mid Jutland (\%) & 23.09 \\
\hline Region North Jutland (\%) & 10.28 \\
\hline $\mathrm{N}$ & 834 \\
\hline
\end{tabular}

Note: Sample was weighted to be face-to-face representative for gender, age, region.

a) For information purposes only; categories were used in the regression analyses.

b) Continuous variable was calculated using category midpoints plus the cap value of the highest income category. It is for information purposes only; categories were used in the regression analyses. 
APPENDIX TABLE 2

Descriptive Statistics of Individual, Household, and Geographic Variables Used in the Analysis of the Hungarian Sample, Mean (SD) or Percent, Weighted

\begin{tabular}{|c|c|}
\hline Variables & Mean (SD) or \% \\
\hline Number of approved nudges $(0-15)$ & $8.44(3.753)$ \\
\hline High approval of System 1 nudges $(\%)$ & 40.17 \\
\hline High approval of System 2 nudges (\%) & 71.56 \\
\hline High approval of Type 1 info campaign nudges (\%) & 72.66 \\
\hline High approval of Type 2 info mandate nudges (\%) & 70.82 \\
\hline High approval of Type 3 default rule nudges (\%) & 44.61 \\
\hline High approval of Type 4 choice architecture nudges (\%) & 27.86 \\
\hline High approval of Type 5 subliminal-advertisement stimuli (\%) & 38.63 \\
\hline Age $^{\text {a) }}$ & $42.75(14.252)$ \\
\hline Age, up to 29 yrs. $(\%)$ & 24.88 \\
\hline Age, $30-39$ yrs. (\%) & 20.21 \\
\hline Age, $40-49$ yrs. (\%) & 18.44 \\
\hline Age, $50-59$ yrs. $(\%)$ & 19.85 \\
\hline Age, $60-69$ yrs. $(\%)$ & 16.62 \\
\hline Male (\%) & 48.18 \\
\hline $\begin{array}{l}\text { Education, } 8 \text { yrs. of elementary or less; finished secondary technical institute, vocational } \\
\text { school }(\%)\end{array}$ & 19.67 \\
\hline Education, secondary vocational, engineering, or grammar school with GCSE (\%) & 41.46 \\
\hline Education, completed college or university $(\%)$ & 38.87 \\
\hline Monthly household income (HUF) ${ }^{\text {b) }}$ & $\begin{array}{c}225,061 \\
(114,905)\end{array}$ \\
\hline Under HUF 80,000 (\%) & 8.43 \\
\hline HUF 80,001-140,000 (\%) & 19.42 \\
\hline HUF $140,001-200,000(\%)$ & 20.15 \\
\hline HUF $200,001-260,000(\%)$ & 17.30 \\
\hline HUF $260,001-320,000(\%)$ & 12.63 \\
\hline HUF $320,001-380,000(\%)$ & 8.52 \\
\hline HUF 380,001 and higher (\%) & 13.54 \\
\hline Social class low $(\%)$ & 18.17 \\
\hline Social class mid $(\%)$ & 49.85 \\
\hline Social class high $(\%)$ & 31.99 \\
\hline Urban residence (\%) & 70.92 \\
\hline Community size, $1-1,000(\%)$ & 7.22 \\
\hline Community size, 1,001-2,000 (\%) & 9.12 \\
\hline Community size, $2,001-5,000(\%)$ & 15.62 \\
\hline Community size, 5,001-10,000 (\%) & 6.26 \\
\hline Community size, $10,001-20,000(\%)$ & 10.69 \\
\hline Community size, $20,001-50,000(\%)$ & 15.73 \\
\hline Community size, over 50,000 (\%) & 18.50 \\
\hline Community size, is Budapest (\%) & 16.86 \\
\hline $\mathrm{N}$ & 852 \\
\hline
\end{tabular}

Note: Sample was weighted to be face-to-face representative for age, gender, region, and settlement size.

a) For information purposes only; categories were used in the regression analyses.

b) Continuous variable was calculated using category midpoints plus the cap value of the highest income category. It is for information purposes only; categories were used in the regression analyses. 
APPENDIX TABLE 3

Descriptive Statistics of Individual, Household, and Geographic Variables Used in the Analysis of the United Kingdom Sample, Mean (SD) or Percent, Weighted

\begin{tabular}{|c|c|}
\hline Variables & Mean (SD) or \% \\
\hline Number of approved nudges $(0-15)$ & $10.28(3.310)$ \\
\hline High approval of System 1 nudges (\%) & 52.54 \\
\hline High approval of System 2 nudges (\%) & 90.76 \\
\hline High approval of Type 1 info campaign nudges (\%) & 87.17 \\
\hline High approval of Type 2 info mandate nudges (\%) & 89.29 \\
\hline High approval of Type 3 default rule nudges (\%) & 53.32 \\
\hline High approval of Type 4 choice architecture nudges (\%) & 44.69 \\
\hline High approval of Type 5 subliminal-advertisement stimuli (\%) & 49.01 \\
\hline Age $^{\text {a) }}$ & $47.23(16.474)$ \\
\hline Age, up to 29 yrs. (\%) & 16.65 \\
\hline Age, $30-39$ yrs. $(\%)$ & 19.46 \\
\hline Age, $40-49$ yrs. (\%) & 18.23 \\
\hline Age, $50-59$ yrs. $(\%)$ & 17.46 \\
\hline Age, $60-69$ yrs. (\%) & 18.74 \\
\hline Age, 70 and older. $(\%)$ & 9.47 \\
\hline Male (\%) & 50.00 \\
\hline Marital status, single (\%) & 26.55 \\
\hline Marital status, married/living with partner (\%) & 61.47 \\
\hline Marital status, divorced/separated/widowed (\%) & 11.98 \\
\hline \multicolumn{2}{|c|}{ Education, secondary school, high school, NVQ levels 1 to 3, etc.; Still in full-time education; } \\
\hline No formal education & 54.19 \\
\hline Education, university degree or equivalent prof. qualification, NVQ level 4, etc. & 34.91 \\
\hline Education, higher university degree, doctorate, MBA, NVQ level 5, etc. & 10.90 \\
\hline Employment, full-time (\%) & 46.06 \\
\hline Employment, part-time (\%) & 12.08 \\
\hline Employment, none (\%) & 41.86 \\
\hline Annual gross household income (GPB) ${ }^{\text {b) }}$ & $32,783(20,201)$ \\
\hline Up to GBP 14,000 & 18.00 \\
\hline GBP $14,001-21,000$ & 15.00 \\
\hline GBP $21,001-28,000$ & 15.00 \\
\hline GBP $28,001-34,000$ & 14.00 \\
\hline GBP $34,001-41,000$ & 11.00 \\
\hline GBP $41,001-48,000$ & 8.00 \\
\hline GBP 48,001-55,000 & 6.00 \\
\hline GBP $55,001-69,000$ & 6.00 \\
\hline GBP 69,001 or more & 8.00 \\
\hline Region North East, Yorkshire, the Humber (\%) & 13.27 \\
\hline Region North West (\%) & 11.99 \\
\hline Region East/West Midlands (\%) & 16.93 \\
\hline Region East of England, South West (\%) & 18.55 \\
\hline Region South East (\%) & 24.99 \\
\hline Region Wales $(\%)$ & 5.70 \\
\hline Region Scotland (\%) & 8.58 \\
\hline Social class A (\%) & 6.83 \\
\hline Social class B (\%) & 20.23 \\
\hline Social class C $(\%)$ & 50.50 \\
\hline Social class D (\%) & 10.32 \\
\hline Social class E (\%) & 12.12 \\
\hline $\mathrm{N}$ & 1,805 \\
\hline
\end{tabular}

Note: Sample was weighted to be face-to-face representative on age, gender, region, and social class. 
a) For information purposes only; categories were used in the regression analyses.

b) Continuous variable was calculated using category midpoints plus the cap value of the highest income category. It is for information purposes only; categories were used in the regression analyses. 
APPENDIX TABLE 4

Descriptive Statistics of Individual, Household, and Geographic Variables Used in the Analysis of the Italian Sample, Mean (SD) or Percent, Stratified

\begin{tabular}{|c|c|}
\hline Variables & Mean (SD) or $\%$ \\
\hline Number of approved nudges $(0-15)$ & $10.73(3.463)$ \\
\hline High approval of System 1 nudges (\%) & 61.40 \\
\hline High approval of System 2 nudges (\%) & 90.28 \\
\hline High approval of Type 1 info campaign nudges (\%) & 88.53 \\
\hline High approval of Type 2 info mandate nudges (\%) & 85.56 \\
\hline High approval of Type 3 default rule nudges (\%) & 62.48 \\
\hline High approval of Type 4 choice architecture nudges (\%) & 47.91 \\
\hline High approval of Type 5 subliminal-advertisement stimuli (\%) & 55.47 \\
\hline Age a) & $40.65(11.593)$ \\
\hline Age, up to 29 yrs. (\%) & 20.38 \\
\hline Age, $30-39$ yrs. $(\%)$ & 25.51 \\
\hline Age, $40-49$ yrs. (\%) & 28.48 \\
\hline Age, $50-59$ yrs. (\%) & 20.65 \\
\hline Age, $60-69$ yrs. (\%) & 4.99 \\
\hline Male (\%) & 52.09 \\
\hline Household size (1-5) & $3.10(1.109)$ \\
\hline Children $(\%)$ & 33.60 \\
\hline Marital status, single (\%) & 63.43 \\
\hline Marital status, married/living with partner (\%) & 30.50 \\
\hline Marital status, divorced/separated/widowed (\%) & 6.07 \\
\hline Education, pre-primary, primary, secondary (\%) & 15.25 \\
\hline Education, higher (\%) & 67.75 \\
\hline Education, university degree $(\%)$ & 17.00 \\
\hline Profession, self-employed, farmer, fisherman (\%) & 20.51 \\
\hline Profession, white collar, blue collar (\%) & 42.24 \\
\hline Profession, student $(\%)$ & 12.01 \\
\hline Profession, housewife (\%) & 9.04 \\
\hline Profession, retired $(\%)$ & 2.43 \\
\hline Profession, temporarily not working, other profession (\%) & 13.77 \\
\hline Household income, monthly, net (EUR) ${ }^{\text {b) }}$ & $1,851(879)$ \\
\hline Up to EUR $1,059(\%)$ & 15.65 \\
\hline EUR $1,060-1,264(\%)$ & 12.96 \\
\hline EUR $1,265-1,549(\%)$ & 16.87 \\
\hline EUR 1,550-1,939 (\%) & 14.84 \\
\hline EUR 1,940-2,454 (\%) & 19.43 \\
\hline EUR 2,455 and more (\%) & 20.24 \\
\hline Region North West (\%) & 26.32 \\
\hline Region North East (\%) & 18.35 \\
\hline Region Centre (\%) & 21.05 \\
\hline Region South (\%) & 22.81 \\
\hline Region Islands (\%) & 11.47 \\
\hline $\mathrm{N}$ & 741 \\
\hline
\end{tabular}

Note: Sample was weighted to be online representative for gender, age, and region; "high approval" denotes approval of half or more of the nudges of each type.

a) For information purposes only; categories were used in the regression analyses.

b) Continuous variable was calculated using category midpoints plus the cap value of the highest income category. It is for information purposes only; categories were used in the regression analyses. 


\begin{tabular}{|c|c|c|c|c|}
\hline & Denmark & Hungary & $\begin{array}{c}\text { United } \\
\text { Kingdom }\end{array}$ & Italy \\
\hline & $\begin{array}{c}\text { Sum of } 15 \\
\text { nudges } \\
\text { Std. Beta }\end{array}$ & $\begin{array}{c}\text { Sum of } 15 \\
\text { nudges } \\
\text { Std. Beta }\end{array}$ & $\begin{array}{l}\text { Sum of } 15 \\
\text { nudges } \\
\text { Std. Beta }\end{array}$ & $\begin{array}{c}\text { Sum of } 15 \\
\text { nudges } \\
\text { Std. Beta }\end{array}$ \\
\hline \multicolumn{5}{|l|}{ Individual measures: } \\
\hline Age, 30-39 yrs. & 0.039 & 0.032 & 0.012 & -0.034 \\
\hline Age, $40-49$ yrs. & -0.062 & -0.064 & -0.026 & -0.001 \\
\hline Age, 50-59 yrs. & 0.036 & 0.014 & -0.038 & 0.090 \\
\hline Age, $60-69$ yrs. & 0.020 & 0.045 & $-0.075 *$ & 0.027 \\
\hline Age, 70 and older & -0.070 & & -0.053 & \\
\hline Male & 0.004 & $-0.072 *$ & $-0.122 * * *$ & $-0.074+$ \\
\hline Married/living with partner & & & 0.043 & -0.042 \\
\hline Divorced/separated/widowed & & & 0.020 & -0.050 \\
\hline High school & -0.028 & & & \\
\hline Lower elementary business school & 0.037 & & & \\
\hline Elementary business school & -0.021 & & & \\
\hline Short graduate & -0.058 & & & \\
\hline Medium graduate /bachelor & 0.062 & & & \\
\hline Longer graduate /university & -0.065 & & & \\
\hline Secondary vocational, engineering or grammar school & & -0.049 & & \\
\hline Completed college or university & & -0.082 & & \\
\hline University degree or equivalent prof. qualification, etc. & & & -0.023 & -0.042 \\
\hline Higher university degree, doctorate, etc. & & & 0.019 & -0.040 \\
\hline Employment, full-time & & & 0.004 & \\
\hline Employment, part-time & & & -0.016 & \\
\hline Profession, white collar, blue collar & & & & 0.069 \\
\hline Profession, student & & & & 0.015 \\
\hline Profession, housewife & & & & 0.019 \\
\hline Profession, retired & & & & 0.011 \\
\hline Profession, not working, other profession & & & & $0.104 *$ \\
\hline \multicolumn{5}{|l|}{ Household measures: } \\
\hline Household size & 0.015 & & & -0.055 \\
\hline Presence of children & & & & 0.010 \\
\hline Number children & 0.022 & & & \\
\hline \multicolumn{5}{|l|}{ Annual gross household income: } \\
\hline 200,000-299,999 DKK & $-0.135 * *$ & & & \\
\hline 300,000-399,999 DKK & $-0.125^{*}$ & & & \\
\hline 400,000-499,999 DKK & $-0.097 *$ & & & \\
\hline $500,000-599,999$ DKK & $-0.088+$ & & & \\
\hline 600,000-699,999 DKK & $-0.090+$ & & & \\
\hline 700,000-799,999 DKK & $-0.152 * *$ & & & \\
\hline 800,000-899,999 DKK & $-0.118^{*}$ & & & \\
\hline $900,000 \mathrm{DKK}$ and more & $-0.085+$ & & & \\
\hline \multicolumn{5}{|l|}{ Monthly household income: } \\
\hline HUF $80,001-140,000$ & & 0.022 & & \\
\hline HUF $140,001-200,000$ & & 0.026 & & \\
\hline HUF $200,001-260,000$ & & $-0.111+$ & & \\
\hline HUF $260,001-320,000$ & & 0.024 & & \\
\hline HUF $320,001-380,000$ & & -0.003 & & \\
\hline HUF 380,001 and higher & & -0.080 & & \\
\hline
\end{tabular}




\begin{tabular}{|c|c|c|c|c|}
\hline & Denmark & Hungary & $\begin{array}{c}\text { United } \\
\text { Kingdom }\end{array}$ & Italy \\
\hline & $\begin{array}{l}\text { Sum of } 15 \\
\text { nudges } \\
\text { Std. Beta }\end{array}$ & $\begin{array}{l}\text { Sum of } 15 \\
\text { nudges } \\
\text { Std. Beta }\end{array}$ & $\begin{array}{l}\text { Sum of } 15 \\
\text { nudges } \\
\text { Std. Beta }\end{array}$ & $\begin{array}{l}\text { Sum of } 15 \\
\text { nudges } \\
\text { Std. Beta }\end{array}$ \\
\hline \multicolumn{5}{|l|}{ Annual gross household income: } \\
\hline GBP $14,001-21,000$ & & & 0.043 & \\
\hline GBP $21,001-28,000$ & & & $0.081 *$ & \\
\hline GBP $28,001-34,000$ & & & $0.069 *$ & \\
\hline GBP $34,001-41,000$ & & & 0.031 & \\
\hline GBP $41,001-48,000$ & & & 0.049 & \\
\hline GBP $48,001-55,000$ & & & 0.034 & \\
\hline GBP 55,001-69,000 & & & 0.053 & \\
\hline GBP 69,001 or more & & & 0.025 & \\
\hline \multicolumn{5}{|l|}{ Monthly net household income: } \\
\hline EUR 1,060-1,264 & & & & 0.050 \\
\hline EUR 1,265-1,549 & & & & 0.075 \\
\hline EUR 1,550-1,939 & & & & $0.135 * *$ \\
\hline EUR 1,940-2,454 & & & & $0.130 *$ \\
\hline EUR 2,455 plus & & & & 0.084 \\
\hline Social class A & & & 0.010 & \\
\hline Social class B & & & -0.032 & \\
\hline Social class $\mathrm{C}$ & & & 0.000 & \\
\hline Social class D & & & -0.023 & \\
\hline Social class high & & 0.079 & & \\
\hline Social class mid & & 0.080 & & \\
\hline \multicolumn{5}{|l|}{ Geographic measures: } \\
\hline Urban residence & & $0.195^{*}$ & & \\
\hline DK Region Zealand & -0.017 & & & \\
\hline DK Region South Denmark & -0.054 & & & \\
\hline DK Region Mid Jutland & 0.023 & & & \\
\hline DK Region North Jutland & 0.015 & & & \\
\hline UK Region North East & & & -0.013 & \\
\hline UK Region North West & & & -0.039 & \\
\hline UK Region Midlands & & & $-0.065^{*}$ & \\
\hline UK Region East of England, South West & & & -0.044 & \\
\hline UK Region Wales & & & 0.013 & \\
\hline UK Region Scotland & & & -0.014 & \\
\hline IT Region North West & & & & $-0.133 * *$ \\
\hline IT Region North East & & & & -0.065 \\
\hline IT Region South & & & & -0.023 \\
\hline IT Region Islands & & & & 0.002 \\
\hline Community size, $1-1,000$ & & 0.079 & & \\
\hline Community size, $1,001-2,000$ & & $0.186^{* *}$ & & \\
\hline Community size, $2,001-5,000$ & & $0.136^{*}$ & & \\
\hline Community size, 5,001-10,000 & & 0.067 & & \\
\hline Community size, $10,001-20,000$ & & 0.002 & & \\
\hline Community size, $20,001-50,000$ & & 0.008 & & \\
\hline Community size, over 50,000 & & 0.001 & & \\
\hline $\mathrm{N}$ & 834 & 852 & 1,805 & 741 \\
\hline \multirow[t]{2}{*}{$\mathrm{R}^{2} / \operatorname{adj} . \mathrm{R}^{2}$} & $0.052 / 0.02$ & $0.057 / 0.03$ & $0.039 / 0.02$ & $0.053 / 0.02$ \\
\hline & 1 & 1 & 3 & 0 \\
\hline F statistic & $1.689 *$ & $2.189 * *$ & $2.392 * * *$ & $1.610^{*}$ \\
\hline
\end{tabular}


